\title{
Welcome Message
}

The organising committee of the $4^{\text {th }}$ Asia Pacific Conference on Educational Integrity warmly welcomes you to the University of Wollongong, New South Wales, Australia for this conference.

To those of you who have participated in previous Asia Pacific Conferences on Educational Integrity, or who have connected through the International Journal for Educational Integrity, this is an opportunity to continue the conversation. To those who are newer to this exciting interdisciplinary field, we look forward to your critical insights and interventions over the coming days ... and beyond. Many of the participants are local, but we are also welcoming people from the United States, Singapore, New Zealand and Canada.

Educational integrity is always topical, highly-charged, of-the-moment, equal parts affective and intellectual, whether the issue being debated is the place of school league tables, the recruitment of international students, the role of the teacher in the 'Googlised' world, the moral remit of the university, the temptation to plagiarise and cheat, or the ancient and pervasive practice of academic 'patronage'. We hope that many of the issues brought to the conference sessions will be hotly debated and potential solutions avidly discussed.

We are not seeking consensus. Our aim in planning this conference is to generate openness of discussion around a topic that traditionally attracts worried conversations about ethics, cheating, transparency, and honesty. We hope to lighten and light up this discussion and move beyond issues of student deficit or the self-righteousness of 'gotcha' policies and detection processes.

By opting for directed and animated discussion rather than the formal presentation of papers, and by welcoming a range of different voices, this conference optimises time and space for free-ranging and sustainable discourse.

Be prepared for surprises!

We hope you find the atmosphere of this conference at Wollongong conducive to intellectual liveliness. We acknowledge that it has taken a bit of effort to get here, and so we know that you'd like to make the most of this opportunity to meet scholars of all types and from all educational sectors who are interested in exploring the concept of educational integrity.

Margaret Wallace and Ruth Walker,

Co-Chairs

$4^{\text {th }}$ Asia Pacific Conference on Educational Integrity 


\section{Contents}

Conference Information 3

Conference Organising Committee $\quad 4$

Keynote Speakers 6

$\begin{array}{ll}\text { Invited Contributors } & 7\end{array}$

The Conference at a Glance $\quad 8$

$\begin{array}{lr}\text { Pre-Conference Workshop Program } & 9\end{array}$

$\begin{array}{lr}\text { Conference Program } & 10\end{array}$

$\begin{array}{ll}\text { Jungle Stalk and Talk } & 12\end{array}$

$\begin{array}{ll}\text { Information on Paper Sessions } & 13\end{array}$

$\begin{array}{ll}\text { Conference One-pagers } & 14\end{array}$

List of Delegates 53 


\section{Conference Information}

\section{Venue}

The conference will be held at the main campus of the University of Wollongong, Northfields Avenue, Wollongong NSW Australia. The UOW campus map can be viewed at: http://www.uow.edu.au/about/campusmap/map5/map.html?20

The pre-conference workshops will be run in Building 41 of main campus. Registration for these workshops will be in the foyer of Building 41, with the workshops starting from room 104.

Registration for the 4APCEI conference will take place in the foyer of Building 20, from 8.30am on Tuesday, 28 September and again from 8:30am on Wednesday, 30 September, 2009.

Building 20: lecture theatres 1 and 5 - Morning registration, welcome and conference opening, keynote presentations, roundtable and debate. Morning and afternoon tea.

Building 41: rooms 104-106 - Pre-conference workshops and the conference discussion paper sessions. Lunch.

\section{Meals}

Morning and afternoon tea will be served in the foyer of Building 20 on Tuesday and Wednesday. Lunches will be served in the foyer of Building 41 . Vegetarian options will be available, and special diet requirements will have been organised following registration requests.

\section{Conference Cocktail Party}

All conference and pre-conference participants are invited to the 4APCEI cocktail party on Monday 28th September from $5 \mathrm{pm}$. This will be held in Building 67 in the McKinnon Dining room, on level 2.

\section{Conference Dinner}

The conference dinner on Tuesday 29th September from $7 \mathrm{pm}$ will be held at the Innovation Campus (iC), which is closer to the beach and about 20 minutes away from main campus. Conference delegates are advised to catch the Gong Shuttle, a free shuttle bus (55A has the most direct route from the Wollongong CBD and $55 \mathrm{C}$ has the most direct route from the main University of Wollongong campus), or take a taxi to the iC. The dinner will be in the iC Central building (on the second floor at the Ocean end), which is the first building on the left from the main road bus stop. All registered conference participants are cordially invited to the dinner. A free bus has been organised to transport delegates after the dinner to the train station or CBD hotels from $9.45 \mathrm{pm}$.

The conference dinner will feature the student video competition award and a performance from Dave Bloustein, guest speaker and comedy writer.

\section{Proceedings}

Conference proceedings are available online at http://www.uow.edu.au/conferences/4APCEI_2009/conferencepapers.html 


\section{Conference Organising Committee}

\section{Conference Co-Chairs}

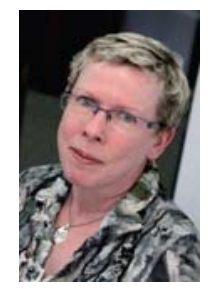

Margaret Wallace teaches in the Faculty of Health \& Behavioural Sciences at the University of Wollongong. In 2008 she received an ALTC citation for 'creating stepping stones to evidence-based practice in nursing by drawing teaching teams into the ongoing process of curriculum development'. Her doctoral research looked at how litigants in a professional disciplinary tribunal applied legally sanctioned criteria to determine what scientific evidence was admissible.

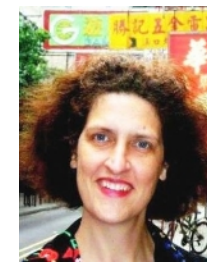

Ruth Walker is interested in the impact of media technologies on critical writing practices, as well as transnational pedagogies. As a Lecturer in Learning Development at the University of Wollongong, she was a recipient of the 2008 ALTC citation 'For sustained work to collaboratively integrate contextualised academic integrity into curricula'. She is currently working on a research project related to new media, academic cultures and writing voice.

\section{Conference Co-secretaries}

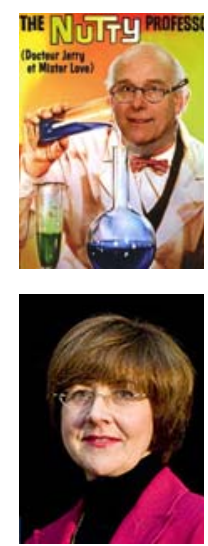

David Griffiths is Foundation Professor of Statistics at UoW and has taught in all Faculties; his postgraduate supervisions have extended beyond half of them. The ubiquitous nature of his disciplinary specialty and a longstanding role in University Governance have strongly informed his views on and participation in Educational Integrity issues.

\section{Conference Editorial and Review}

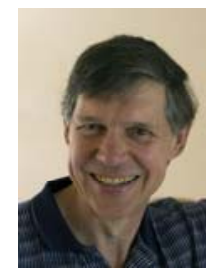

Celeste Rossetto is a language and academic skills lecturer who works on the central campus at UOW and on the satellite campus at Moss Vale. Celeste's area of research focuses on the interrogation of the forces that impact student learning in a variety of contexts. In 2008, she was a recipient of the Vice-Chancellor's Award for Outstanding Contribution to Teaching and Learning. many books and articles on nonviolence, dissent, information issues, scientific controversies, democracy and other topics. 


\section{Conference Committee}
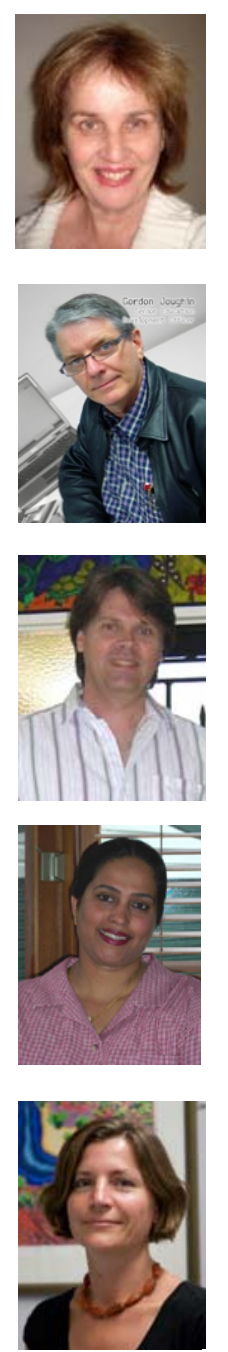

Bronwyn James is a senior lecturer in Learning Development at the University of Wollongong and a recipient of the 2008 ALTC citation 'For sustained work to collaboratively integrate contextualised academic integrity into curricula'. Her research relates to student writing practice and peer review of Academic Language and Learning provisions in the national Higher Education sector.

Gordon Joughin a senior lecturer in the Academic Development Unit at the University of Wollongong with a particular interest in the influence of assessment on learning in higher education.

Paul Moore is a language and academic skills lecturer at the University of Wollongong. He has a PhD in Applied Linguistics and is recipient of the 2008 ALTC citation 'For sustained work to collaboratively integrate contextualised academic integrity into curricula'. His research interests include second language acquisition, sociocultural/activity theory and applied conversation analysis.

Meeta Chatterjee Padmanabhan is a lecturer in Learning Development, University of Wollongong. Her doctoral research involves textual integration from sources and includes discussions on the complex negotiation of academic language by users of English as an Additional Language in constructing an academic identity and voice. In 2009, she was a recipient of the Vice-Chancellor's Award for Outstanding Contribution to Teaching and Learning.

Alisa Percy is a lecturer in academic language and learning at the University of Wollongong and a recipient of the 2008 ALTC citation 'For sustained work to collaboratively integrate contextualised academic integrity into curricula'. Her doctoral research uses the lens of governmentality to examine the ethical constitution of the learning advisor in Australian higher education.

\section{Acknowledgements}

The Committeee would like to thank the following:

Isla Bowen

Chris Brewer

Christine Brown

Damien Considine

Jo Failes

Alison Pepper

Helen Simpson

Venkat Yanamandram

Kelly Andrews and Anthony Petre (Booklet Design)

Katie Freund and Chris Moore (Student Competition) 


\section{Keynote Speakers Anna Broinowski}

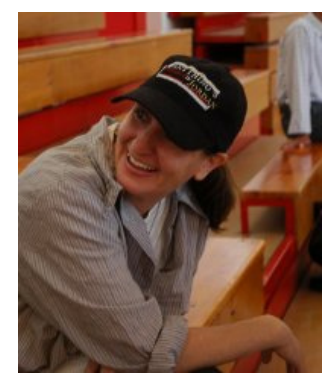

Anna Broinowski is a multiple AFI award winning director who has been making films since 1995. Her documentaries include FORBIDDEN LIE\$, HELEN'S WAR, SEXING THE LABEL and HELL BENTO!!, all of which screened theatrically. Awards include the 2007 Rome Film Fest 'Cult' Prize, the Al Jazeera International Film Festival 'Golden Award', the San Francisco Film Festival Special Jury prize, the Russian Film Critics' Best Feature Award, 3 Australian Film Institute Awards, 2 Australian Film Critics' Awards, the 2008 NSW Premier's Literary Award, and Best Director at Films des Femmes in France. Anna published a bilingual Japanese/English play, The Gap in 1996 (Currency Press) and worked for a year as a project manager at the Australian Film Commission in 2001. Following the successful US release of FORBIDDEN LIE\$, which won the Writers' Guild of American Best Non-fiction Screenplay award in 2008, Anna is now developing a slate of feature films. She is attached to direct the forthcoming satirical drama, PLEASE EXPLAIN, about Pauline Hanson. Anna is currently completing her doctoral studies at Macquarie University.

\section{KEYNOTE ADDRESS Filming the Con}

An examination of the ethical, cultural and artistic challenges involved in the making of FORBIDDEN LIE\$, a dramatized documentary about Chicago con-artist turned hoax author, Norma Khouri. When filmmaker Anna Broinowski set out to film Norma Khouri in 2005, she thought the author would prove that her discredited memoir, Forbidden Love, was based on the truth. Instead, Norma conned Anna too, sucking her into a deceptive parallel universe in which lies are truth, spin is justified, and 'faction' sells. But should we only judge Norma in the end, or are her publishers, the media, the law, Western and Jordanian politicians, and even the filmmaker herself equally complicit?

\section{John Lesko}

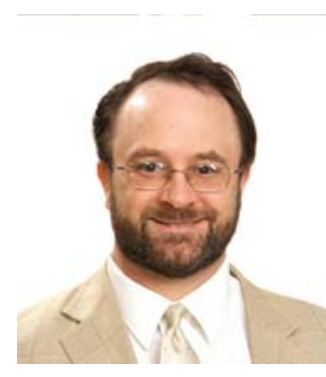

Dr J ohn P. Lesko is Associate Professor of Applied Linguistics, Saginaw Valley State University, USA. For the past two years, he taught in Oman as Visiting Professor and Fulbright Scholar at Al Buraimi College. He is the editor of the scholarly journal Plagiary: Cross-Disciplinary Studies in Plagiarism, Fabrication, and Falsification, and his interest in plagiary follows postgraduate research on the dynamics of derivative writing which he conducted at the University of Edinburgh, Scotland from 1994-1997.

KEYNOTE ADDRESS Derivative Writing: Templates for Success, Recipes for Disaster

Texts can be a learning template for students composing in a foreign language, or for students who may be unfamiliar with the academic discourse called for in university level course work. Speechwriters, perhaps with the complicity of the speech-givers, or perhaps not, might see textual derivation as a formula for success as they appropriate the language of a previous speech and incorporate it into "new" oratory. Scientists might find it tempting to report research results by simply "plugging in" their data into an already existing article template which they have borrowed from published authors. "Boilerplate" verbiage in legal documents and bureaucratic settings is more easily copied than created anew. There are many contexts and situations in which derivation can and should be used to achieve certain ends. And yet there are also contexts and situations where such derivation has in effect become a recipe for disaster, the derivation serving to hinder rather the further the publication of discourse, serving to ignite a public relations fiasco rather than enhance an institutional image, or threatening to end a talented individual's career, stymieing and stifling ingenuity rather than promoting an individual's chances for success. Select cases of derivative writing will be used to exemplify the variables and dynamics involved when previous texts are appropriated for re-use in a "new" text. 


\section{Invited contributors}

\section{Workshop Facilitators - International students and academic integrity}

\section{Ken Cruickshank}

Ken Cruickshank is a Senior Lecturer in TESOL in the Faculty of Education at the University of Wollongong. He taught in schools for many years in Australia and overseas, and lectured at UTS and The University of Sydney before his appointment at the University of Wollongong. His research interests include teaching English to Speakers of other languages; bilingual and community languages education; and literacy practices in multilingual contexts; teacher education for cultural diversity.

Paul Moore (see Conference Organising Committee, p5)

\section{Workshop Facilitators - Accomodating students with disabilities}

\section{Kim Draisma}

Kim Draisma is Head of Learning Development at the University of Wollongong, where she has taught for 24 years. She established the first Learning Development services at UoW in 1985, and since that time has developed an interest in working with students with disability, in particular those with learning disabilities or mental health disabilities. She recently received a Vice-Chancellor's Award for Outstanding Contribution to Teaching and Learning for her involvement with a project in the Faculty of Engineering.

\section{Petria McGoldrick}

Petria McGoldrick is the Manager of the Disability Services Unit at the University of Wollongong. She has worked in disability service provision for the past 28 years within both government and non-government sectors. Her work areas have included higher education, employment and occupational rehabilitation, service management, community development and health promotion. Petria has university qualifications in Psychology and Science (Mental Health).

\section{Debate Participants - 'Should we be taught?'}

\section{Moderator - Allen Clark}

Allen Clark has championed ethical journalism for almost a quarter of a century. He's been a radio broadcaster, radio and TV journalist and political staffer in the Illawarra, most recently working as Network News Director for WIN Television.

\section{Negative - Smiths Hill High School Debating Team}

Natalie Connor, Solange Handley and Nathan J ohnson

Affirmative - The Tertiary Trio

Tracey Bretag, University of South Australia; Jennifer Woolsey and Paul Stuckey, University of Wollongong

\section{Roundtable 1 Facilitators - Participatory or social media and academic integrity}

Katie Freund

Katie is a PhD candidate in the School of Social Science, Media and Communication at the Faculty of Arts, University of Wollongong. She is writing her dissertation on fan-made remix videos (known as "vids"), where television and film footage is edited to music, and often convey meanings not intended by their original creators.

\section{Chris Moore}

Chris is a lecturer in the School of Social Studies, Media and Communication at the University of Wollongong, teaching in the Bachelor of Communication and Media Studies Digital Communication specialisation. His research interests include copyright and intellectual property reform, digital games and teaching and learning with social and participatory media. You can follow him on Twitter as DIGC_Dr_Moore.

\section{Roundtable 2 Facilitators - Role playing ethical dilemmas}

Bronwyn James and Margaret Wallace (see Conference Organising Committee, pp4-5)

\section{Dinner Speaker}

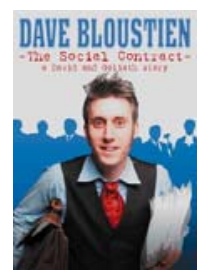

\section{Dave Bloustein}

Dave Bloustein [http://www. bloustein.com/home.shtml] is a comedian, writer and improvisor. He's part of the award winning writing team on Good News Week, a 2009 Moosehead Award recipient and has performed everywhere from Enmore to Edinburgh. 


\section{The Conference at a Glance}

Monday

$28^{\text {th }}$ September

\begin{tabular}{|c|c|c|c|c|}
\hline & $28^{\text {th }}$ September & & & \\
\hline 8.30 & & \multicolumn{3}{|c|}{ Registration } \\
\hline 9.00 & & \multicolumn{3}{|c|}{$\begin{array}{c}\text { Welcome to Country } \\
\text { Barbara Nicholson } \\
\text { Official PTB welcome } \\
\text { DVC (Academic) Prof. Rob Castle }\end{array}$} \\
\hline $9.15-10.15$ & & \multicolumn{3}{|c|}{$\begin{array}{l}\text { Keynote Speaker } \\
\text { Anna Broinowski, Filming the Con }\end{array}$} \\
\hline $10.15-11.00$ & & \multicolumn{3}{|c|}{$\begin{array}{l}\text { Morning Tea } \\
\text { 'stalk and talk' }\end{array}$} \\
\hline $11.00-12.00$ & & $\begin{array}{l}\text { Session 1A } \\
2 \text { papers }\end{array}$ & $\begin{array}{l}\text { Session } 1 \mathrm{E} \\
2 \text { papers }\end{array}$ & $\begin{array}{l}\text { Session } \mathbf{~} \mathbf{C} \\
2 \text { papers }\end{array}$ \\
\hline $12.00-1.00$ & & $\begin{array}{l}\text { Session 2A } \\
2 \text { papers }\end{array}$ & $\begin{array}{l}\text { Session } 2 \mathbf{E} \\
2 \text { papers }\end{array}$ & $\begin{array}{l}\text { Session } \mathbf{2 C} \\
2 \text { papers }\end{array}$ \\
\hline $1.00-2.00$ & & \multicolumn{3}{|c|}{ Lunch } \\
\hline $2.00-3.30$ & \multirow[t]{3}{*}{$\begin{array}{l}\text { Pre-conference } \\
\text { Workshops }\end{array}$} & $\begin{array}{c}\text { Roundtable } \mathbf{1} \\
\text { Participatory or social media and } \\
\text { academic integrity. }\end{array}$ & \multicolumn{2}{|c|}{$\begin{array}{c}\text { Roundtable } 2 \\
\text { What would you do? Role playing } \\
\text { ethical dilemmas }\end{array}$} \\
\hline $3.30-4.00$ & & \multicolumn{3}{|c|}{$\begin{array}{l}\text { Afternoon Tea } \\
\text { 'stalk and talk' }\end{array}$} \\
\hline $4.00-5.00$ & & $\begin{array}{c}\text { Session } 3 \mathbf{A} \\
1 \text { paper }\end{array}$ & $\begin{array}{l}\text { Session 3B } \\
1 \text { paper }\end{array}$ & $\begin{array}{c}\text { Session } 3 C \\
1 \text { paper }\end{array}$ \\
\hline 5.00 & Cockail Party & \multicolumn{3}{|c|}{ APFEI meeting } \\
\hline 7.00 & & \multicolumn{3}{|c|}{ Conference Dinner } \\
\hline
\end{tabular}

Wednesday $30^{\text {th }}$ September

Registration

Keynote Speaker

John Lesko, Derivative Writing

\begin{tabular}{|c|c|c|}
\hline \multicolumn{3}{|c|}{$\begin{array}{l}\text { Morning Tea } \\
\text { 'stalk and talk' }\end{array}$} \\
\hline $\begin{array}{c}\text { Session } 4 A \\
2 \text { papers }\end{array}$ & $\begin{array}{l}\text { Session 4B } \\
2 \text { papers }\end{array}$ & $\begin{array}{c}\text { Session } 4 C \\
2 \text { papers }\end{array}$ \\
\hline $\begin{array}{c}\text { Session 5A } \\
2 \text { papers }\end{array}$ & $\begin{array}{c}\text { Session 5B } \\
2 \text { papers }\end{array}$ & $\begin{array}{c}\text { Session } \mathbf{5 C} \\
2 \text { papers }\end{array}$ \\
\hline \multicolumn{3}{|c|}{ Lunch } \\
\hline $\begin{array}{c}\text { Session } 6 A \\
3 \text { papers }\end{array}$ & $\begin{array}{c}\text { Session 6B } \\
3 \text { papers }\end{array}$ & $\begin{array}{c}\text { Session } 6 \mathrm{C} \\
3 \text { papers }\end{array}$ \\
\hline \multicolumn{3}{|c|}{$\begin{array}{l}\text { Afternoon Tea } \\
\text { 'stalk and talk' }\end{array}$} \\
\hline \multicolumn{3}{|c|}{$\begin{array}{l}\text { Debate } \\
\text { d we be taught?' } \\
\text { ol vs university, } \\
\text { 'Focus on Teachin }\end{array}$} \\
\hline
\end{tabular}

\section{Conference Close}




\section{Pre-conference Workshop}

\section{MONDAY 28th September Building 41, Room 104}

\section{Exploring what works: inclusivity and educational integrity}

\begin{tabular}{|c|lc|}
\hline 13.30 & Registration - Tea and coffee & Foyer of Building 41 \\
\hline $14: 00$ & WELCOME Yvonne Kerr, Dean of Students, University of Wollongong \\
\hline 14.15 & $\begin{array}{l}\text { WORKSHOP OUTLI NE Paul Moore } \\
\text { Outline of workshop process and introduction to facilitators }\end{array}$ & Building 41, rooms $104 \& 107$ \\
\hline 14.20 & Session 1 Parallel Workshops
\end{tabular}

\section{International students}

Ken Cruickshank \& Paul Moore

- What issues of educational integrity, particularly relating to inclusivity, have your university/department recently experienced with regard to international students?

- What policies and practices have emerged at your university to deal with these issues?

- What do you value most about your university's current practices related to international students?

- What's working particularly well at your university?

- What needs to change?

\section{Accommodating students with disabilities}

Kim Draisma \& Petria McGoldrick

This workshop provides an opportunity for practitioners, including academics, to engage with others around issues of academic integrity and inclusivity, as they relate to students with disabilities. The workshop contextualises case studies within the framework of the Disability Standards for Education. The outcome expected of the workshop is enhanced understanding of the need to address academic integrity in finding solutions to problems of inclusivity. Moving beyond reasonable accommodation to find unique strategies to address the needs of all stakeholders is the 'art' of inclusivity.
Identify barriers to change noted above and turn them into goals. What steps can be taken to reach these goals?

16.00 WRAP UP Ken Cruickshank, Paul Moore, Kim Draisma \& Petria McGoldrick.

Whole group feedback on both workshops
Group feedback on case studies, issues arising and strategies identified 


\section{Conference Program}

\section{TUESDAY 29th September}

\begin{tabular}{|c|c|}
\hline 8.30 & Foyer of Building 20 \\
\hline 9.00 & $\begin{array}{l}\text { Welcome to country } \\
\text { Barbara Nicholson } \\
\text { Welcome to the University of Wollongong } \\
\text { Professor Rob Castle, Deputy Vice Chancellor (Academic), University of Wollongong }\end{array}$ \\
\hline 9.15 & $\begin{array}{l}\text { Keynote Speaker ANNA BROINOWSKI, 'Filming the con' } \quad \text { Building } 20 \text {, lecture theatre } 1 \\
\text { An examination of the ethical, cultural and artistic challenges involved in the making of FORBIDDEN } \\
\text { LIE\$, a dramatized documentary about Chicago con-artist turned hoax author, Norma Khouri. }\end{array}$ \\
\hline 10.15 & Morning Tea 'stalk and talk' \\
\hline
\end{tabular}

Building 41, rooms 102, $104 \& 107$

\section{SESSION 1: Parallel Papers}

11.00 1A-1: The customer isn't always right: limitations of "customer service" approaches to education, or why Higher Ed is not Burger King

1A-2: Determining outcomes for academic misconduct: is it more important to be consistent or fair?

12.00 2A-1: Faculty ethics unveiled: scholarship - et tu, Brute?

2A-2: Ethical tensions in a disability label?
1B-1: Judgments about plagiarism and plagiarising students in institutional definitions

1B-2: Criminal intent or cognitive dissonance: how does self plagiarism fit into academic integrity?

2B-1: Can we reliably determine intent in cases of plagiarism?

2B-2: The perception of referencing and plagiarism amongst students coming from Confucian heritage cultures
1C-1: Whistle-blowing experiences: can we really do anything?

1C-2: The Integrity of integration: the ethics of exchange student welfare in undergraduate programmes at a French higher education institution

2C-1: Teaching ethics across the university

2C-2: Scholarly practice the Australian way: an academic skills course for postgraduate students

13.00

Lunch

Foyer of Building 41

SESSION 2: Roundtables

Building 20, lecture theatres $1 \& 5$

\begin{tabular}{|c|c|c|}
\hline 14.00 & $\begin{array}{l}\text { Roundtable } \mathbf{1} \\
\text { Participatory or social media and } \\
\text { academic integrity }\end{array}$ & $\begin{array}{c}\text { Roundtable } 2 \\
\text { What would you do? } \\
\text { Role-playing ethical dilemmas }\end{array}$ \\
\hline 15.30 & Afternoon Tea 'stalk and talk' & Foyer of Building 20 \\
\hline
\end{tabular}

SESSION 3: Parallel Papers

Building 41, rooms 102, $104 \& 107$

\begin{tabular}{|c|c|c|c|}
\hline 16.00 & $\begin{array}{l}\text { 3A-1: Partnering with the } \\
\text { academy to enhance } \\
\text { educational integrity: lessons } \\
\text { learnt at the coalface } \\
\text { 3A-2: Issues of inclusivity for } \\
\text { online distance learners: an } \\
\text { academic literacy perspective }\end{array}$ & $\begin{array}{l}\text { 3B-1: Back-translation: the } \\
\text { latest form of plagiarism } \\
\text { 3B-2: Creating confidence: } \\
\text { developing academic skills and } \\
\text { information literacy behaviours } \\
\text { to support the precepts of } \\
\text { tertiary academic performance }\end{array}$ & $\begin{array}{l}\text { 3C-1: Decline in academe } \\
\text { 3C-2: Pathways into bullying: } \\
\text { The place of educational } \\
\text { integrity }\end{array}$ \\
\hline 17.00 & \multicolumn{3}{|l|}{ APFEI meeting } \\
\hline 19.00 & $\begin{array}{l}\text { CONFERENCE DI NNER } \\
\text { Dave Bloustein, guest speak }\end{array}$ & . & $\begin{array}{l}\text { npus, University of Wollongong } \\
\text { ompetition award. }\end{array}$ \\
\hline
\end{tabular}




\section{WEDNESDAY 30th September}

\begin{tabular}{|l|lr|}
\hline 8.30 & Registration & Foyer of Building 20 \\
\hline 9.15 & $\begin{array}{l}\text { Keynote Speaker JOHN LESKO } \\
\text { 'Derivative writing: templates for success, recipes for disaster' }\end{array}$ & Building 20, lecture theatre 1 \\
\hline $\mathbf{1 0 . 1 5}$ & Morning Tea 'stalk and talk' & Foyer of Building 20 \\
\hline
\end{tabular}

SESSION 1: Parallel Papers

Building 41, rooms 102, $104 \& 107$

\begin{tabular}{|c|c|c|c|}
\hline 11.00 & $\begin{array}{l}\text { 4A-1: The assessment of } \\
\text { ethics } \\
\text { 4A-2: Dialogue and } \\
\text { disputation: exploration in } \\
\text { the ethics of argumentation }\end{array}$ & $\begin{array}{l}\text { 4B-1: The various incarnations } \\
\text { of an online academic integrity } \\
\text { module, or whose responsibility is } \\
\text { it anyway? } \\
\text { 4B-2: Links are not enough: using } \\
\text { originality reports to improve } \\
\text { academic standards, compliance } \\
\text { and learning outcomes among } \\
\text { postgraduate students }\end{array}$ & $\begin{array}{l}\text { 4C-1: The role of the university } \\
\text { academic-integrity advisor } \\
\text { 4C-2: Co-creative learning: } \\
\text { creating inclusive processes for } \\
\text { learning through co-operative } \\
\text { inquiry }\end{array}$ \\
\hline 12.00 & $\begin{array}{l}\text { 5A-1: How is research on } \\
\text { academic plagiarism } \\
\text { conducted in China? } \\
\text { 5A-2: Embedding academic } \\
\text { integrity at the University of } \\
\text { Wollongong }\end{array}$ & $\begin{array}{l}\text { 5B-1: Embedding plagiarism } \\
\text { detection within an automated } \\
\text { submission system } \\
\text { 5B-2: The effectiveness of } \\
\text { plagiarism detection software as a } \\
\text { learning tool in academic writing } \\
\text { education }\end{array}$ & $\begin{array}{l}\text { 5C-1: Pursuing mediocrity: } \\
\text { academics should be ashamed } \\
\text { 5C-2: Reminiscences: academic } \\
\text { freedom, fairness in evaluation, and } \\
\text { educational integrity }\end{array}$ \\
\hline 13.00 & Lunch & & Foyer of Building 41 \\
\hline
\end{tabular}

SESSI ON 3: Parallel Papers

Building 41, rooms 102, $104 \& 107$

14.00 6A-1: Taking action on academic integrity at one Australian university

6A-2: Research apprenticeship: Is this the answer to inadvertent plagiarism in undergraduate students' writings?

6A-3: [to be announced]
6B-1: A space odyssey: the implications of moving the writing centre into the virtual world

6B-2: Electronic portfolios: balancing learning and assessment

6B-3: We know it when we see it" is not good enough: toward a standard definition of plagiarism that transcends theft, fraud, and copyright
6C-1: Managing university reputations

6C-2: Plagiarism, ethics and education: where to now?

6C-3: [to be announced]

SESSI ON 4: Debate Topic: 'Should we be taught?' Building 20, lecture theatre 1

16.00 Team A (affirmative): Tracy Bretag (senior lecturer, UniSA), Jennifer Woolsey (undergraduate student, UOW) and Paul Stuckey (postgraduate student, UOW)

Team B (negative): Smiths Hill High School debating team: Natalie Connor, Solange Handley and Nathan Johnston 


\section{Jungle Stalk and Talk Sessions}

\section{Stalk and talk quatrain}

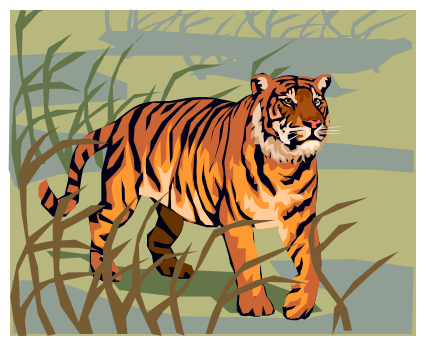

If your inner beast is yearning for a bit of social learning, raise a snout, a claw or paw. "I'd like a herd of six or more"!

In a group of fellow creatures you become each others' teachers. In the café or in the sun lions, zebras, snakes are one.

Hoot or squeak, growl or hiss, keep abreast of papers missed.

Bear your thoughts and go free- range. Plan some future projects-strange!

\section{Prosaic paraphrase}

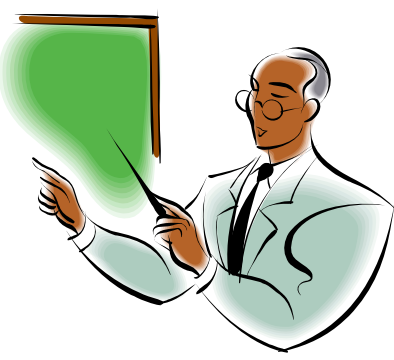

Form groups

with conference participants with the same animal symbol on their name tags.

\section{Meet}

at the indicated times in your conference program at the designated places.

\section{Exchange}

ideas about the papers that you have heard.

\section{Network}

with fellow group members for future projects.

\section{Reference}

James, B. \& Broderick, M. (2009) Stalk and Talk Quatrain, accessed 15/08/2009. idiotpoems@growlspace.edu.au

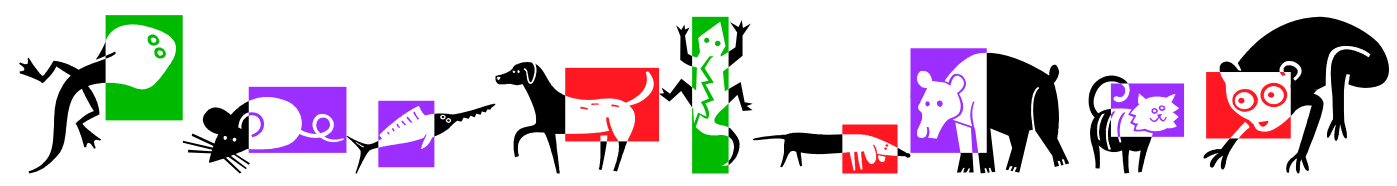




\section{Information for the paper sessions}

\section{Discussants}

- Read the paper beforehand!

- The author posed two discussion questions. You get to present a third one. Write it on the board.

- You get to open the session with a comment. Aim to speak 1 to 2 minutes and be graceful when you're cut off at 3 minutes.

- Read the notes for moderators and try to assist the moderator.

\section{Authors}

- The discussant will open the session. Then you will have an opportunity to reply or comment. Aim to speak 1 to 2 minutes and be graceful when you're cut off at 3 minutes.

- You're not giving a talk - you're participating in a discussion. You've had your say in your paper. Try to spend most of the session listening.

- You might find it useful to keep a record of key points raised during the session. You can take notes yourself or ask another participant to do this for you.

- $\quad$ Read the notes for moderators and try to assist the moderator, most likely by being exceedingly brief and encouraging others to comment.

\section{Moderators}

General Principles

- Your goal as moderator is to foster a stimulating discussion.

- You should aim to give everyone an opportunity to speak.

- You should attempt to prevent anyone dominating or hogging the discussion.

- You should encourage expression of diverse viewpoints.

- You should try to keep the discussion focused on the discussion questions.

- Your role should primarily be moderating the discussion, not contributing to it. If you have a lot you want to say about the topic, get someone else to be the moderator.

\section{Suggestions}

- As people arrive, make sure everyone has a 1-pager.

- Begin by inviting each participant to introduce themselves - names and affiliations only. Introduce yourself first.

- Have a timer with a buzzer. (You can be the timekeeper or have someone else do it.)

- Introduce the discussant. Time: 3 minutes maximum. Be firm.

- Author response: 3 minutes maximum. Be firm.

- Subsequent contributions to discussion: 2 minutes maximum per person

- An optional procedure after the discussant and author's opening comments: go around the group, inviting each person to comment for up to one minute.

- When some participants begin to take a second turn, ask those who haven't spoken yet if they want to say anything.

- Pay special attention to limiting contributions by the author. Try to prevent the session becoming question-and-answer.

- $\quad$ Keep the focus on the discussion questions.

- At the end of the session, thank the author, discussant and all participants.

\section{Other participants}

- $\quad$ Read the 1-pager. If possible, read the paper.

- Be prepared to offer a comment, but don't feel obliged.

- Read the notes for moderators and try to assist the moderator. 


\section{One-pagers (alphabetical list)}

\begin{tabular}{|c|c|c|}
\hline Author/s & Paper Title & Page \\
\hline Paul Amis & $\begin{array}{l}\text { The integrity of integration: the ethics of exchange } \\
\text { student welfare in undergraduate programmes at a } \\
\text { French higher education institution }\end{array}$ & 16 \\
\hline Peter Bowden & Teaching ethics across the university & 17 \\
\hline $\begin{array}{l}\text { Tracey Bretag and } \\
\text { Margaret Green }\end{array}$ & $\begin{array}{l}\text { Determining outcomes for academic misconduct: is } \\
\text { it more important to be consistent or fair? }\end{array}$ & 18 \\
\hline $\begin{array}{r}\text { Meeta Chaterjee and } \\
\text { Paul Moore }\end{array}$ & $\begin{array}{l}\text { Issues of inclusivity for online distance learners: an } \\
\text { academic learning support perspective }\end{array}$ & 19 \\
\hline Peter Curtin & Managing university reputations & 20 \\
\hline Julianne East & $\begin{array}{l}\text { Taking action on academic integrity at one } \\
\text { Australian university }\end{array}$ & 21 \\
\hline Teddi Fishman & $\begin{array}{l}\text { "We know it when we see it" is not good enough: } \\
\text { toward a standard definition of plagiarism that } \\
\text { transcends theft, fraud, and copyright }\end{array}$ & 22 \\
\hline John Furedy & $\begin{array}{l}\text { Reminiscences of the University of Sydney } \\
\text { psychology department's discipline-focused } \\
\text { education of young John (1958-65) under O'Neil's } \\
\text { god professorial reign (1945-65): academic } \\
\text { freedom, fairness in evaluation, and educational } \\
\text { integrity }\end{array}$ & 23 \\
\hline Gabrielle Grigg & $\begin{array}{l}\text { Judgments about plagiarism and plagiarising } \\
\text { students in institutional definitions }\end{array}$ & 24 \\
\hline $\begin{array}{r}\text { R. Todd Hartle, Lindy } \\
\text { Kimmins and Henk } \\
\text { Huijser }\end{array}$ & $\begin{array}{l}\text { Criminal intent or cognitive dissonance: how does } \\
\text { self plagiarism fit into academic integrity? }\end{array}$ & 25 \\
\hline Michelle Horn & $\begin{array}{l}\text { Whistleblowing experiences: can we really do } \\
\text { anything? }\end{array}$ & 26 \\
\hline Clair Hughes & The assessment of ethic & 27 \\
\hline Michael Jones & Back-translation: the latest form of plagiarism & 28 \\
\hline C Nick Kalman & Pursuing mediocrity: academics should be ashamed & 29 \\
\hline $\begin{array}{l}\text { Lindy Kimmins and } \\
\text { Adrian Stagg }\end{array}$ & $\begin{array}{l}\text { Creating confidence: developing academic skills and } \\
\text { information literacy behaviours to support the } \\
\text { precepts of tertiary academic performance }\end{array}$ & 30 \\
\hline $\begin{array}{l}\text { James Lee and } \\
\text { Charles Slumber }\end{array}$ & $\begin{array}{l}\text { The role of the university Academic Integrity } \\
\text { Advisor }\end{array}$ & 31 \\
\hline Gordon Lingard & $\begin{array}{l}\text { Embedding plagiarism detection within an } \\
\text { automated submission system }\end{array}$ & 32 \\
\hline Fande Liu & $\begin{array}{l}\text { How research on academic plagiarism in China is } \\
\text { conducted: a preliminary investigation in the recent } \\
\text { change in the style of writing in an academic journal }\end{array}$ & 33 \\
\hline $\begin{array}{r}\text { Pauline Lysaght with } \\
\text { Yvonne Kerr and Lucia } \\
\text { Tome }\end{array}$ & $\begin{array}{l}\text { Embedding academic integrity at the University of } \\
\text { Wollongong }\end{array}$ & 34 \\
\hline $\begin{array}{r}\text { Grace McCarthy and } \\
\text { Ann Rogerson }\end{array}$ & $\begin{array}{l}\text { Links are not enough: using originality reports to } \\
\text { improve academic standards, compliance and } \\
\text { learning outcomes among postgraduate students }\end{array}$ & 35 \\
\hline
\end{tabular}


Ursula McGowan

Susan R. Madsen and James H. Davis

Ksenija Napan

Deborah Osborne

Alisa Percy, Venkat Yanamandram and Sandra Humphrey

Barbara Ramirez

Gail Ring

Susan Robinson

Kim R. Sawyer, Jackie Johnson and Mark Holub

Sandra Seymour

Brad Stappenbelt and Chris Rowles

Wendy Sutherland-Smith and Sue Saltmarsh

Kirsten Wahlstrom, Helen Johnston and Chris Steketee

Dallas Wingrove and Kylie Budge

Daniel E. Wueste and Teddi Fishman

Molly Yang and Stephen Lin

J on Yorke, Kathryn Lawson and Graham McMahon
Research apprenticeship: Is this the answer to inadvertent plagiarism in undergraduate students' writings?

Faculty ethics unveiled: scholarship-Et tu, brute?

Co-creative learning: creating inclusive processes for learning through co-operative inquiry integrity

The various incarnations of an online academic integrity module, or whose responsibility is it anyway?

A space odyssey: the implications of moving the writing center into the virtual world

Electronic portfolios: balancing learning and assessment

Explorations in the Ethics of Argumentation

Decline in academe

The effectiveness of plagiarism detection software as a learning tool in academic writing education

Plagiarism, ethics and education: where to now?

Scholarly practice the Australian way: an academic skills course for postgraduate students

Partnering with the academy to enhance educational integrity: lessons learnt at the coalface

The customer isn't always right: limitations of "customer service" approaches to education, or why higher education is not Burger King

The perception of referencing and plagiarism 作 cultures

Can we reliably determine intent in cases of 


\title{
The integrity of integration: the ethics of exchange student welfare in undergraduate programmes at a French higher education institution
}

Paul Amis*

\begin{abstract}
Experiences of an Australian exchange student at Sciences Po, a French elite educational institution, are used to illustrate some of the problems that can arise when features of the local institutional culture are not effectively communicated to visiting students.
\end{abstract}

\section{Key I deas}

- Exchange students often are ill-equipped to negotiate unfamiliar administrative systems.

- Expectations about educational integrity can vary considerably between different cultures.

- "Pedagogical liberty" at Sciences Po may allow what students feel are abuses to occur without an official avenue for bringing about change.

Discussion Question 1 Is it always best practice to provide students with full information about syllabus, assessments and the like, or does pedagogical liberty to do things differently have a place?

Discussion Question 2 What can be done to support exchange students who seem to be victims of both inadequate cultural knowledge and abusive treatment? 


\title{
Teaching ethics across the university
}

\author{
Peter Bowden \\ The University of Sydney, Australia
}

\begin{abstract}
Nobody will ever claim that we can teach people to be ethical. So why should we try? One answer, of course, is that universities expect some ethical knowledge in our graduates - graduate attributes is the common term. A more satisfying answer is that we can add to the knowledge and skills of people who want to live and work within an ethical environment, and who may be prepared to put effort toward that environment once they graduate. We can also provide a greater certainty on issues that may be ethically controversial within their organisations or professions. To provide these skills however, we need to expand significantly on many current teaching practices, including managing disclosures in the public interest, making codes of ethics effective; distinguishing right from wrong; organisational and legislative changes, optimum class sizes and teacher capabilities.
\end{abstract}

\section{Key I deas}

- $\quad$ Research tells us that people are basically moral; also that they want to work within a moral environment. These are the reasons for providing the necessary knowledge and skills.

- $\quad$ Research also tells us that the most effective way of identifying wrongdoing is to have people who are aware of that wrong bring it into the open. It is termed whistleblowing.

- Whistleblowing will be a component of most courses. But whistleblowers are usually crucified. Also the legislation that protects them is inadequate. The courses need to tell them how to protect themselves; how to use the legislation as best they can, and motivate them to agitate for strengthening the legislation. This is much wider than current teaching practice.

- Another capability is developing effective code of ethics. Codes however, are often regarded as managerial exhortations, designed for the organisation's benefit or to attract favourable publicity. The extensive research on what makes codes effective relevance and participation primarily, but also widening coverage of many current codes, does need to be included.

- "Relevance" here is the assessment or anticipation of the ethical issues a profession or industry faces. In short, codes, and their teaching, need be discipline specific.

- The last few years has seen an "exponential" growth in ethics based regulation, organisational practices and legislation. Students entering the workforce need to know these changes.

- Telling right from wrong: This is the province of moral theory, but unfortunately, moral philosophers have disagreed for over 2000 years. They are still engaged in an "internecine warfare" on the three major theories - utilitarianism, deontology and virtue. And they do not teach codes, whistleblowing, or organisational practices

- $\quad$ But ethical problems in a profession arise mostly within the profession. At USyd there are over 20 departments teaching ethics, mostly by discipline skilled lecturers. How do they decide right from wrong? And how do they teach students? Take a degree in philosophy?

- $\quad$ Ethical issues are more effectively discussed in small groups. But some undergraduate classes are $100-200$ or more students. How to manage?

- $\quad$ Another issue might be including an ethics component in every appropriate teaching unit in the qualification? Or do we teach one ethics unit per degree?

- If the purpose behind teaching ethics is to empower those who want to strengthen ethical practices, then they will possibly need additional skills? Any ideas?

Discussion Question 1 Can a department of philosophy handle the ethical teaching? At CSU there is a proposal to embed a philosopher in each discipline

Discussion Question 2 Ethics could be the only topic taught across a university. Can we ensure some consistency? 


\title{
Determining outcomes for academic misconduct: is it more important to be consistent or fair?
}

\author{
Tracey Bretag and Margaret Green \\ University of South Australia
}

\begin{abstract}
This paper analyses data from a Health Sciences faculty at an Australian university to determine if outcomes for breaches of academic integrity were applied consistently and/or fairly. The analysis concludes that it is appropriate at times for there to be a difference between the identified severity of an academic misconduct incident and the final outcome imposed. The paper argues that while it is important for universities to have clear policy on this issue, it is just as important for those in charge of applying that policy to be adequately trained and deeply committed to both the academic integrity process and to the complex needs of students. We conclude by stressing that a rigid adherence to a rules-based approach in dealing with breaches of academic integrity will not necessarily ensure fairness.
\end{abstract}

\section{Key I deas}

- It is vital that universities have a clear and detailed policy outlining appropriate outcomes for breaches of academic integrity.

- This policy should be supported by a strong community of practice which provides mentoring to decision-makers so that this policy is executed with both consistency and fairness.

Discussion Question 1 Which is more important: consistency or fairness of outcome for academic integrity breaches?

Discussion Question 1 How can consistency and fairness of outcome for academic integrity breaches be ensured? 


\title{
I ssues of inclusivity for online distance learners: an academic learning support perspective
}

\author{
Meeta Chaterjee and Paul Moore \\ University of Wollongong, Australia
}

\begin{abstract}
Inclusivity is one form of educational integrity that is enshrined as an abiding principle in higher education irrespective of mode of delivery or educational program. In course provision, it might take the form of providing equal access to diverse groups of learners. In on-campus contexts, systems are in place to ensure (not unproblematically) that inclusivity is practised. Distance learners, because of their various commitments and the diverse competence and skills they bring to their studies, are a highly heterogeneous group. 'Inclusivity' in this context could have different meanings. In the present paper, we interpret the term 'inclusivity' to mean greater access and support to students, regardless of their learning contexts. In order to explore ways of enabling access to academic learning support we have explored the ODL literature to uncover how academic support services are envisioned in the literature (if at all), and to imagine how an academic learning support initiative within a program/subject might be conceived to contribute to better outcomes for online distance students.
\end{abstract}

\section{Key I deas}

- ODL literature often treats learning support as a small subset of "learner support", which includes technical and other advice to learners;

- Learning support is often constructed as the provision of generic and/or remedial resources or interventions;

- Models which address ODL individual learners as well as groups in both proactive and reactive ways appear to hold the most potential for learning support, but these also draw heaviest on institutional resources.

Discussion Question 1 What unique challenges are there in providing academic learning support to online distance students?

Discussion Question 2 What models or principles are there which might address these challenges? 


\title{
Managing university reputations
}

\author{
Peter Curtin
}

\begin{abstract}
There has been a failure to recognise the effects of commercial pressure on university administration, and a failure to recognise the different and incompatible goals of commerce and education. To the extent there is conflict and competition between the goals of education and commerce, short term commercial considerations seem to be paramount. Reputation management which brings short term commercial success includes suppression of dissent and criticism, and the covering up of misconduct and wrongdoing in universities. Reputation management which allows dissent and criticism leading to the exposure of wrongdoing, and then allows reform of university administrations, results in longer term improvement in the achievement of educational goals. A long term reputation for integrity may come at a short term commercial price. The competition for Asian students studying abroad has resulted in the compromise of standards of university integrity, and has spawned some spectacular financial losses on overseas campuses.
\end{abstract}

\section{Key I deas}

- Universities have changed significantly and now compete in a global market for fee paying students, however the university systems of administration have not yet adapted to the new challenges and risks.

- University internal justice systems are focused on the protection of the university's reputation rather than on protecting the integrity of the university, or the human rights of students and staff.

Discussion Question 1 Should the right of a university to protect its reputation from criticism or damage be limited by ethical considerations?

Discussion Question 2 Do universities need a national independent judicial tribunal for issues of conduct and integrity in tertiary education? 


\title{
Taking action on academic integrity at one Australian university
}

\author{
Julieanne East \\ La Trobe University, Australia
}

\begin{abstract}
Despite all the work put into writing policies to reduce academic misconduct, all the writing of guidelines for how to acknowledge, and all the declarations of how academic integrity is valued, few Australian universities could say with confidence that they have a holistic, integrated approach to dealing with academic misconduct and academic integrity. One Australian university, for example, has a well-written policy which clearly outlines lecturer responsibilities, yet that university has not monitored whether staff are aware of these responsibilities and if they are implementing them. Given the heavy workload of lecturers, why would lecturers seek out policy and/or bother to carefully read it when it seems peripheral to their research and teaching? Engaging lecturers in the topic of academic integrity requires more than a good policy and a check list. Through a distributed leadership initiative, an action research project in one faculty of this university was set up to engage lecturers in taking on their responsibilities in ways that are appropriate for their practice. In this paper I review the actions taken by the lecturers and reflect on the progress of the project.
\end{abstract}

\section{Key I deas}

- Academic integrity can enable the discrimination between academic dishonesty and errors of academic convention

- La Trobe University has a well-written policy, but not all lecturers are aware of their responsibilities, eg. Faculty of Education

- An integrated approach assures implementation of academic integrity processes

- Policy, practice, resources, assessment, penalty, monitoring, reviewing are aligned

- Action research is a project tool for taking action

- An action research project has been set up in the Faculty of Education

- Reflection reveals what worked and what didn't work.

Discussion Question 1 With regard to academic integrity, at your institution what is done to ensure:

- students and staff are aware of their responsibilities?

- resources available for staff and students are appropriate and effective?

- decisions about suspected breaches of academic integrity are consistent? 


\title{
"We know it when we see it" is not good enough: toward a standard definition of plagiarism that transcends theft, fraud, and copyright
}

\author{
Teddi Fishman \\ Clemson University, USA
}

\begin{abstract}
Many of the assumptions that inform the ways we respond to issues of plagiarism are based in laws and traditions that pertain to stealing or to copyright. Laws about stealing, however, assume key concepts that are at odds with the conceptual realities of plagiarism. The notion of taking something, for instance, carries with it the concomitant idea that the rightful owner is deprived of the use of that thing. Laws about copyright are similarly derived from the notion of a physical text being duplicated to make additional (physical) copies to be sold, implying that if copyright is violated, the rightful owner suffers (financial) harm. Neither set of laws appropriately addresses plagiarism, however, which can occur without depriving the author/owner of the work or the right to profit from it. This paper will differentiate the elements of plagiarism from those of theft and copyright violations, and attempt to define plagiarism in terms that accurately describe its essential elements.
\end{abstract}

\section{Key I deas}

- $\quad$ Plagiarism does not $=$ theft. It is not the same as "taking."

- $\quad$ Plagiarism does not $=$ copyright violation. It does not necessarily deprive the owner of his/her rights.

- $\quad$ Plagiarism needs its own set of elements (similar to the elements of a crime).

Discussion Question 1 What are the essential elements of plagiarism?

Discussion Question 2 If we define plagiarism strictly, do we also need to come up with a new vocabulary to describe other things that currently seem to fall, by default, under the heading of plagiarism (such as "self plagiarism")? 


\title{
Reminiscences of the University of Sydney psychology department's discipline-focused education of young J ohn (1958-65) under O'Neil's god professorial reign ( 1945-65): academic freedom, fairness in evaluation, and educational integrity
}

\author{
John Furedy
}

\begin{abstract}
This paper is a modification of and some additions to an oral paper given in 20081 to philosophers and psychologists most of whose current thinking is along the lines of a post-modern, instrumentalist approach to knowledge and higher education. The paper's (long) title shamelessly plagiarizes from the title of the book by the much more eminent Donald Horne. The approach I advocate, and look back to (perhaps with glasses that are somewhat rose tinted) is one that characterized O'Neil's department. The approach was pre-modernist in a number of differentiating respects that included complete academic freedom, education rather than indoctrination, and fairness in the evaluation only of academic performance rather than of personal beliefs and attitudes. These conditions, rather than those of such features as "inclusiveness", I argue, are necessary for integrity in higher education. These are also the conditions which are largely satisfied in competitive elitist sports and games, especially in Australia.
\end{abstract}

Discussion Question 1 If the competitive, elitist approach is good enough for sports and games, why is it not good enough for those who volunteer to engage, either as students or teaching staff, in higher education?

Discussion Question 2 In higher education, should we aim for equality of opportunity or equality of outcomes?

\footnotetext{
${ }^{1}$ Furedy, J. 2008. On the relevance of philosophy for scientific psychological research: Pre-Socratic, Socratic, Aristotelean, and Andersonian influences on the Sydney psychology department (1945-65). Current Projects Seminar, School of Philosophical and Historical Inquiry and The Centre for Time, University of Sydney, October 27, 2008 Available at: http://www.psych.utoronto.ca/users/furedy/Papers/ra/Seminar08_15.doc
} 


\title{
J udgments about plagiarism and plagiarising students in institutional definitions
}

\author{
Gabrielle Grigg \\ The University of Melbourne, Australia
}

\begin{abstract}
Plagiarism is perceived as a serious problem for the higher education sector, indicated by the fact that all 39 Australian universities have a policy on plagiarism. It is therefore timely to ask: What are the characteristics of these policies? As an example of policy characteristics, this presentation discusses the types of attitudes inherent in the language of policy in the institutional definitions of Australian universities. It is argued that policies are not neutral, but rather contain judgments that show underlying attitudes, a situation neither surprising nor necessarily undesirable for plagiarism. These judgments contribute towards creating the university stance on important topics such as plagiarism and may clarify this stance for those new to the institution. University definitions of plagiarism have been analysed via Appraisal (Martin and White, 2005). The results indicate that the definitions contain a significant amount of judgment appraising plagiarism and plagiarising students negatively in terms of truthfulness and ethics. Students are predominantly appraised negatively in terms of their diligence, capability or adherence to accepted norms. Variation in the mix and emphasis of judgements in institutional definitions was found across the university sector.
\end{abstract}

\section{Key I deas}

- Policies include underlying attitudes towards the policy topic and to the institution's students.

- These attitudes can be illuminated via linguistic analysis of the judgments in text.

- These judgments can be helpful in declaring the university's stance towards, and framing of, plagiarism.

- There is a range of attitudes expressed via judgments in institutional definitions of plagiarism across Australian universities.

Discussion Question 1 What do you think the crucial functions of an institutional definition of plagiarism are, and how could analysing judgments contribute to understanding and honing these functions?

Discussion Question 2 What do you consider important elements in an institution's stance on plagiarism - and might the emphasis of these differ between universities? 


\title{
Criminal intent or cognitive dissonance: how does self plagiarism fit into academic integrity?
}

\author{
R. Todd Hartle, Lindy Kimmins and Henk Huijser \\ University of Southern Queensland, Australia
}

\begin{abstract}
The discourse of plagiarism is speckled with punitive terms not out of place in a police officer's notes: detection, prevention, misconduct, rules, regulations, conventions, transgression, consequences, deter, trap, etc. This crime and punishment paradigm tends to be the norm in academic settings. The learning and teaching paradigm assumes that students are not filled with criminal intent, but rather are confused by the novel academic culture and its values. The discourse of learning and teaching includes: development, guidance, acknowledge, scholarly practice, communicate, familiarity, culture. Depending on the paradigm adopted, universities, teachers, and students will either focus on policies, punishments, and ways to cheat the system or on program design, assessments, and assimilating the values of academia. Self plagiarism is a pivotal issue that polarises these two paradigms. Viewed from a crime and punishment paradigm, self plagiarism is an intentional act of evading the required workload for a course by re-using previous work. Within a learning and teaching paradigm, self plagiarism is an oxymoron. We would like to explore the differences between these two paradigms by using self plagiarism as a focal point.
\end{abstract}

\section{Key I deas}

- The paradigm of crime and punishment considers plagiarism to be a deliberate act of cheating.

- The paradigm of learning and teaching considers plagiarism to be a sign that students have not been assimilated into the academic culture.

- Depending on the paradigm assumed, universities will either focus on policies, review procedures, and penalties or on program design, academic development and support, and embedding academic values.

- Academic staff will either focus on course specifications, detection, and student intention or on constructivist alignment, assessment design, and learning opportunities.

- Students will either focus on seeking loopholes, being conscientious, working the system, or on learning objectives, course content, and academic values.

- Responses to self plagiarism are ideal focal points for examining these two paradigms as they are highly polarised.

Discussion Question 1 Self plagiarism - is it an oxymoron as the same assignment may meet two different outcomes, or is it an attempt to gain two grades from putting in effort for one?

Discussion Question 2 Is submitting part of your doctoral dissertation as a journal article also self plagiarism, and should we be punished ourselves?

Discussion Question 3 is there a correlation between time spent on a piece of assignment, and learning outcomes achieved? Is so, why? 


\title{
Whistleblowing experiences: can we really do anything?
}

\author{
Michelle Horn*
}

\begin{abstract}
Academic institutions, corporations and government departments in the west commonly espouse guidelines for practising ethical behaviour for the benefit of students, clients and citizens. However, individuals who report on wrongdoing often suffer damaging reprisals, thereby thwarting the ostensible goal of lofty guidelines.
\end{abstract}

\section{Key I deas}

- $\quad$ Although higher education institutions have anti-corruption policies, there are major discrepancies between policy and practice.

- $\quad$ Those who speak out against unethical practices often suffer for their efforts.

Discussion Question 1 Does the law give institutions a way to say "we support" and "we comply" without addressing fundamental problems?

Discussion Question 2 What should an ethical person do when they attempt to highlight a problem to a superior or outside authority and are met with silence or coverup, tantamount to tacit support for unethical practices?

* Michelle Horn is a pseudonym. 


\title{
The assessment of ethics
}

\author{
Clair Hughes \\ The University of Queensland, Australia
}

\begin{abstract}
That Australian universities value the development of qualities broadly related to ethics is evidenced through their inclusion in institutional statements of graduate attributes (GA). Early GA implementation strategies largely emphasised the mapping of specific attributes against existing programs or courses. There is now a growing acknowledgement that authentic implementation does not occur unless GAs are embedded in assessment. The assessment of graduate attributes is a problematic and challenging task a situation attributed partly to difficulties in conceptualising GAs in ways that facilitate their operationalisation in teaching and assessment and partly to inadequacies in the development of assessment strategies and instruments. For many academics, the moral dimension of ethics so intensifies the assessment challenge that they are often not assessed at all. While these difficulties are acknowledged, this paper argues the case for the explicit inclusion of ethics in course teaching and assessment plans and illustrates some of the contexts, including the student university learning experience, in which the development and assessment of ethics can be undertaken.
\end{abstract}

\section{Key I deas}

- Attributes that might be termed "Ethics" are widely addressed in institutional statements of graduate attributes (The ALTC National GAP project).

- While some statements refer explicitly to ethical practice in (future) professional lives, others have added application in personal and social contexts.

- Early implementation strategies emphasised mapping GAs against existing curricula often perfunctory or otherwise problematic (Sumison \& Goodfellow 2004).

- Assessment is now acknowledged as providing strongest evidence of successful implementation (Barrie 2004), but is problematic (Hughes \& Barrie in review) because of inadequate or naïve GA conceptualisations (Barrie 2006) or inadequate assessment strategies or instruments (Carroll 2004).

- There is a need for explicit inclusion of ethics in planning for teaching, learning and assessment.

- The assessment of ethics involves (1) articulation of learning outcomes, (2) the selection of assessment methods (3) the basis for judgements and (4) the role of students in the assessment process.

- Many current assessment contexts and practices already provide opportunities for assessment of "Ethics" - e.g. contributions to group work.

- Explicit attention to the behaviours that encompass Ethical Awareness can:

- more overtly articulate institutional values and expectations in everyday teaching and learning practices; and

- $\quad$ support the collection of evidence of GA implementation effectiveness.

Discussion Question 1 What teaching, learning and assessment behaviours suggest opportunities for the development and assessment of ethics?

Discussion Question 2 How can students be actively engaged in the assessment of ethics? 


\title{
Back-translation: the latest form of plagiarism
}

\author{
Michael J ones \\ University of Wollongong, Australia
}

\begin{abstract}
This paper addresses the continuing problem of plagiarism which, as a form of academic misconduct, has plagued pedagogy for generations. Little has changed in the way students employ the various methods of plagiarism, until now. Traditionally detection technologies have kept pace with the technologies students use to cheat. However, the technologies students can harness to assist them in plagiarising have now leapt forward another generation, making the detection of plagiarism very difficult to detect. Further, it seems unlikely that technology can advance to a state sufficient to bridge the gap. This new method of plagiarism utilises the intercultural technique of back-translation. This is where a passage of text is taken, verbatim, and translated to a foreign language, French for instance. It is then re-translated back into English using the same technique. Through a discussion of how students use translation technologies to change and conceal their copied text, the paper exposes back-translation as a method of plagiarising and concealing it. The paper concludes with a discussion on methods that teachers could adopt for reducing the potential of back-translation misuse. These methods include: use of current materials, writing up in class, and tighter control over resources.
\end{abstract}

\section{Key I deas}

- Students can and do use more advanced methods of cheating to avoid modern plagiarism detection.

- New technologies are permitting students to cut and paste whole sections of text without the necessity of citing.

- Enhanced awareness by academics is needed to catch these instances of plagiarism.

Discussion Question 1 How can back-translation be detected in student submissions?

Discussion Question 2 How advanced/large is the problem? 


\title{
Pursuing mediocrity: academics should be ashamed
}

\author{
C Nick Kalman*
}

\begin{abstract}
Compared to students, the big cheats are academics. They show gross prejudice in hiring decisions, and anything else relevant to advancement. Second-raters need not fear for their future: they just need to polish their bootlicking. Don't complain unless you want to be a loser in this competition.
\end{abstract}

\section{Key I deas}

- Any academic who's been around can tell you many a story about bias and abuse.

- The way to get ahead is to suck up or at least just keep your head down and avoid making waves.

Discussion Question 1 Why are academics so exercised by student cheating when they see their colleagues bending the rules all the time?

Discussion Question 2 Why are some people silly enough to try to do something about it?

* C Nick Kalman is a pseudonym. 


\title{
Creating confidence: \\ developing academic skills and information literacy behaviours to support the precepts of tertiary academic performance
}

\author{
Lindy Kimmins and Adrian Stagg \\ University of Southern Queensland, Australia
}

\begin{abstract}
Fostering the skills required for students to access and utilise information in a manner consistent with the expectations of tertiary assessment has been the drive for collaboration between the Faculty Librarian and the Academic Learning Skills Lecturer at the University of Southern Queensland. Mapping key areas of convergence in information literacy and academic skills has led to a model of integrated instruction and academic support based on the belief that creating a foundation of skills in these areas leads to a commensurate level of self-efficacy. By building skill and confidence levels, especially in students making a transition to university in their first year, staff can influence learning behaviours including those which may to lead to breaches of academic integrity. This model can be accessed by all students which is especially important to ensure parity of program experience for off-campus cohorts who are often expected to undertake study with a greater degree of autonomy than their on-campus peers, yet who, just like their oncampus peers, often need an opportunity to develop their academic skill base.
\end{abstract}

\section{Key I deas}

- There is a convergence between information literacy skills and academic learning skills.

- $\quad$ Student transition including the development of appropriate learning behaviours can be made easier by the provision of support in the development of these skills and subsequent increase in self-efficacy.

- The skills are best developed in an integrated model developed through a collaborative approach between practitioners.

- There is a requirement for the model to be inclusive in that it must be available to all student cohorts.

Discussion Question 1 Where is the interface between information literacy and academic learning skills?

Discussion Question 2 How does scaffolding of information literacy skills and academic learning skills help reduce academic integrity issues? 


\title{
The role of the university Academic Integrity Advisor
}

\author{
James Lee and Charles Slumber \\ Queens University, Canada
}

\begin{abstract}
Queen's University is a comprehensive, research-intensive, but highly decentralized institution located in Kingston, Ontario, Canada. As part of a new institutional paradigm embracing the broader, proactive principles of academic integrity, a new university role was created, known as the Academic Integrity (Al) Advisor to the VicePrincipal (Academic). Focusing on three key areas - awareness, education, and policy and procedures - the Advisor has broad responsibility for Al policy development, information gathering and sharing, and for promotion of the values of academic integrity. Free from the challenges of handling specific cases, the Al Advisor can focus on establishing bestpractices in the three key areas, by drawing on the research, experiences, and analysis of other institutional practices from the Canadian and international environments. Numerous university-wide initiatives targeted at students, instructors and faculty members, and administrators, have brought together a variety of institutional partners to raise the profile of Al across the university. By building on a principle of broad institutional inclusion, this position thus provides a dynamic lens through which a variety of academic-integrity issues faced within and by universities, both centralized and decentralized, can be discussed and effectively addressed.
\end{abstract}

\section{Key I deas}

- The desire to change university culture from academic dishonesty to academic integrity on campus led to the creation of the Academic Integrity Advisor role.

- The role of the Al Advisor at Queen's University is unique among all universities in Canada.

- The role of the Al Advisor can encompass the academic-integrity paradigm in its broadest sense as it pertains to the university's entire academic mission - including service, teaching, and research.

- The Al Advisor can bring together institutional partners to effect changes in policies and procedures, to develop proactive educational programs, and to increase awareness through outreach activities and educational campaigns.

- The Al Advisor provides a effective model for operating in a decentralized university environment.

- The Al Advisor role could be a viable model that, if enhanced, could lead to a more centralized process for handling academic-integrity issues.

- $\quad$ Future challenges include adapting to new technologies available to both students and instructors and creating a culture of academic integrity that will become an integral part of lifelong learning.

Discussion Question 1 Do you see a role for an Academic Integrity Advisor at your institution and what kind of role could he/she play?

Discussion Question 2 How could this role be made even more effective overall in addressing each of the focus areas (awareness, education, and policies and procedures)? 


\title{
Embedding plagiarism detection within an automated submission system
}

\author{
Gordon Lingard \\ University of Technology, Sydney, Australia
}

\begin{abstract}
Collusion and copying between students doing computer programming assignments has been a significant problem for many years. In an effort to combat this many plagiarism systems have been written that have worked reasonably well to detect copies. A problem with such systems is that they only identify assignments that are copies of each other. They cannot tell who has originated the code and who has copied. Since 2003 a system has been used at UTS that embeds collusion detection information within the logs used by a submission system the students use to submit assignments. This has created a detailed audit trail that allows for the determination of who has created and who has copied code. Beyond that, the information can be mined to see how students network form to exchange information.
\end{abstract}

\section{Key I deas}

- Collusion detection - programming assignments

- Combining collusion detection with assignment submission system

- Studying the way collusion networks form. How information is exchanged between students.

Discussion Question 1 The network detection systems were deployed in a third semester programming subject. There is evidence that many students are colluding from the time they begin their degree to complete assignments. By the time they reach their third semester they are so far behind that they have little option but to continue cheating if they are to pass the subject. What can be done to discourage students from doing this at the very beginning of their degree?

Discussion Question 2 Over the last couple of years there been a marked shift in the way students cheat. Instead of copying off each other they are now increasingly using many of the rent-a-coder sites to get their assignments done. For the students cheating the advantage of this is its cheap, easy to use and almost impossible to detect, let alone prove. This is proving to be a very corrupting temptation. What can be done about this? 


\title{
How is research on academic plagiarism in China conducted? A preliminary investigation of the recent change in the style of writing in an academic journal
}

\author{
Fande Liu \\ The University of Adelaide, Australia
}

\begin{abstract}
This paper reports on the findings from a study on an academic journal Academics in China. The journal, launched in 1986, is representative of academic journals in China in the field of the humanities and social sciences. It deals with the issue of academic plagiarism and other forms of academic corruption. By analysing articles about academic plagiarism published in this journal in 1999, 2000, 2004 and 2008, it provides statistics and analysis on the perception of Chinese academics about plagiarism within Chinese academe. It found that open discussion about academic plagiarism and other academic corruption in China dramatically increased after 2000 as: (1) the number of articles dealing with academic plagiarism in this period increased dramatically compared to the previous period, and (2) more authors were concerned about this issue than they were before 2000. Although much concern has been raised about this issue since the mid 1990s, no empirical study seems to have been conducted on plagiarism by Chinese academics.
\end{abstract}

\section{Key I deas}

- The increasing concern of Chinese academics for academic plagiarism and other academic issues is an important part of the transition of a society from a planned economy to a market economy.

- The transition of Chinese academics including the style of Chinese scholarship is not obvious although an increasing concern for the issue mentioned has arisen.

- The study of academic plagiarism and other forms of academic corruption by Chinese academics are more subjective rather than objective, thus less empirical study on the issues mentioned has been carried out.

- The unpreparedness and low quality of Chinese academics to conduct studies on the issue of plagiarism led to the current situation of Chinese scholarship on these issues.

Discussion Question 1 Is there a convergence between academic conventions in the West and those in China?

Discussion Question 2 How do Chinese academics define academic plagiarism? 


\title{
Embedding academic integrity at the University of Wollongong
}

\author{
Pauline Lysaght, Yvonne Kerr and Lucia Tome* \\ University of Wollongong, Australia
}

\begin{abstract}
This paper provides a preliminary report on a project designed to determine how effectively values associated with academic integrity have been embedded in the learning and teaching environment at UOW. Five key values have been formally identified at UOW: honesty, trust, fairness, respect and responsibility. These values are based on those espoused by the Centre for Academic Integrity (CAI) at Duke University in North Carolina and are recognised as central to academic honesty. Academic staff at UOW, charged with responsibilities for shaping educational policy and implementing, monitoring and reviewing processes that support the development of academic integrity across the student population, have taken part in the project. Through their responses to surveys and focus group discussions, a broad understanding of academic integrity and the ways in which it may be supported is emerging.
\end{abstract}

\section{Key I deas}

- A shared understanding of the complexity of the term "academic integrity" is a necessary pre-requisite for developing a framework that rests on ethical principles and that will support a culture of honesty.

- Rather than a punitive approach, our focus must be on a learning environment that encourages critical thinking and that gradually supports the development of the skills this involves.

- Two useful approaches to encouraging academic integrity involve teaching disciplinespecific language and acknowledging the importance of written communication, whilst shaping assessment tasks to reduce the likelihood of dishonest behaviour.

- Procedures for managing alleged academic misconduct should clearly discriminate between actions based on ignorance and those stemming from malice.

Discussion Question 1 How can learning experiences that support the development of academic integrity be structured across the courses offered at UOW?

Discussion Question 2 What strategies can be employed by educational institutions to accommodate the needs of an increasingly diverse student body - is it possible for primary, secondary and tertiary institutions to collaborate in this endeavour?

\footnotetext{
*The authors thank the other two members of the Working party Student Support for Learning Subcommittee — David Vance and Kim Draisma - for valuable discussions. 


\title{
Links are not enough: using originality reports to improve academic standards, compliance and learning outcomes among postgraduate students
}

\author{
Grace McCarthy and Ann Rogerson \\ University of Wollongong, Australia
}

\begin{abstract}
Training students on the interpretation of originality reports generated by an electronic evaluation tool can assist with the reduction of unintentional plagiarism. An initial trial by the Sydney Business School, a postgraduate faculty of the University of Wollongong, has demonstrated that a proactive approach, based on pedagogical principles, can have a positive impact on the improvement of student writing skills when compared to a retributive justice approach reliant on a student's ability and initiative in accessing internet support resources. This paper argues that higher education should not rely on links to internet based information, policies, and systems, to educate students in highlighting the seriousness and consequences of allegations of plagiarism. The trial at Sydney Business School supplemented the use of an electronic plagiarism detection tool with instructions given by the lecturer, related to the subject assessment tasks, and discussions both on the benefits of using originality reports and how to use these reports effectively to improve students' writing, thus providing positive motivation and consistent academic support and guidance. This paper proposes that this more proactive 'informed' approach can ultimately achieve better results for students, academics, and institutions.
\end{abstract}

\section{Key I deas}

- Students are overwhelmed with information when they first arrive at university, particularly from overseas. Links to plagiarism policies are often not used or understood. Recent literature indicates a shift in Australian universities towards education on good practice in academic writing.

- Sydney Business School first trialled the use of Turnitin in 2006, using it to help students to see where their assignments were over-reliant with direct quotations, whether or not these were correctly acknowledged.

- The trial was successful both in terms of student perceptions and performance. The trial was extended in 2008 and made mandatory for all subjects in the faculty in 2009. Guidance was given to staff on how to interpret the originality reports consistently and fairly.

- In 2009, a further trial demonstrated how student performance improved earlier and faster when students were given more information and support on academic writing, including how to use originality reports to help avoid plagiarism.

Discussion Question 1 Is it acceptable for universities to rely on definitions, policies and threats of serious consequences to ensure students avoid plagiarism? What are the alternatives?

Discussion Question 2 How do you ensure academic consistency in the use of antiplagiarism detection tools? 


\title{
Research apprenticeship: is this the answer to inadvertent plagiarism in undergraduate students' writings?
}

\author{
Ursula McGowan \\ The University of Adelaide, Australia
}

\begin{abstract}
To deal with inadvertent plagiarism, a conceptual framework based on an apprenticeship model for undergraduate education is proposed here. It aims to provide students with guidance, feedback and time to develop (1) an understanding of the rationale for the requirement of referencing conventions in university education and (2) tools for lifelong language learning and skills in emulating the writings of the experts in their disciplines.
\end{abstract}

\section{Key I deas}

1. Rationale for academic conventions

The rationale for the requirements of citations and referencing in tertiary assignments generally relies on the concept that the unattributed use of another's words, works or ideas amounts to 'stealing'. There are ambiguities in interpreting this concept that may, in many cases, be responsible for students' unintentional plagiarism. See http://www.adelaide.edu.au/clpd/online/learningmodules/avoidingPlagiarism/player.html

\section{Tertiary learning as induction into research}

The referencing requirements might be better understood by students if the rationale were more expressly underpinned by an understanding that the major characteristic of university learning is the culture of research, and that undergraduate study is an initiation into that culture. However, at undergraduate level, many students, and sometimes staff as well, may fail to make this connection to research.

\section{The implicit made explicit}

Nevertheless it is a subconscious, implicit expectation, that student assignments must uphold academic integrity by fulfilling the requirements of citation and referencing conventions of the genre of research writing. Students need to know explicitly that the qualities of integrity and transparency are basic characteristics of research, and that they apply not only to data, methods of calculation and the evaluation of the results in an experimental or survey-based research project, but also to assignments that are entirely based on existing literature.

4. Tools for life-long language learning

Once the basic rationale is understood in terms of research, the second step is to help students to develop tools for learning the language and codes of research writing as appropriate for their disciplines. I suggest that students can be helped to develop skills in absorbing and using the language that is typically used for evidence-based writing within their specific disciplines by 'harvesting' language items from their readings.

\section{Apprenticeship}

I propose that most students in transition to tertiary study would benefit from an induction into the culture of research and the discipline-specific language for research writing; and that this induction therefore be part of mainstream curricula. A conceptual framework promoting the concept of student apprenticeship into the academic culture is shown at www.adelaide.edu.au.clpd/plagiarism/. Undergraduate students are pictured as apprentice researchers who move through several stages towards becoming competent researchers. An essential aspect of apprenticeship is that novices need time for development and growth and the opportunity to take risks, make mistakes and learn through constructive feedback on their errors. In this model, students' inadvertent plagiarism would be utilised as a learning tool, rather than subjected to punitive investigation.

Discussion Question 1 What assistance will staff need if an apprenticeship approach is implemented?

Discussion Question 2 What are the barriers to implementation? Who should have the responsibility of expert in the expert-apprentice relationship? 


\title{
Faculty ethics unveiled: scholarship-et tu, Brute?
}

\author{
Susan R. Madsen \\ Utah Valley University, USA \\ James H. Davis \\ University of Notre Dame, USA
}

\begin{abstract}
Little actual research has been conducted to explore the ethics of the faculty of higher education. A review of the literature has discovered four primary categories of faculty ethics, which include scholarship, teaching, service, and professional (e.g., consulting, treatment of colleagues and peers). This paper will focus on the scholarship category and includes research (e.g., authorship, conflicts of interest, plagiarism/citingincluding self-plagiarism, ethical approval, research design, redundant publications, misconduct, accuracy, personal criticism of others) and review of other's work as a reviewer or editor (e.g., unbiased, speed/timeliness, accuracy, responsibility, objectivity, confidentiality, conflicts of interest). The purpose of this paper is to survey and classify key ideas in the literature, present research propositions, and outline ideas for future research in this area.
\end{abstract}

\section{Key I deas}

- An emerging and critical topic of educational integrity research focuses on the exploration of the ethics of faculty within higher educational settings.

- Five obstacles frame the discussion around why academics do not focus on investigating ethics within their own profession: fear, double standards, personal connections, official channels, and power (based upon Martin's (2007) academic integrity obstacles).

- The ethics of faculty scholarship and research can be summarized into four broad categories: idea generation and ownership (idea); the research methodology and process (process); management of research relationships (relationship); and professional behavior in scholarship (professional).

Discussion Question 1 What do you think are the most critical areas to address today within the faculty ethics umbrella?

Discussion Question 2 What might be effective interventions or solutions in raising awareness of this issue on college/university campuses throughout the world? 


\title{
Co-creative learning: \\ creating inclusive processes for learning through co-operative inquiry
}

\author{
Ksenija Napan \\ Unitec, New Zealand
}

\begin{abstract}
This paper focuses on an innovative way of using cooperative inquiry processes for learning and assessment. Cooperative inquiry is usually used as an empowering and participatory research methodology for personal transformation. This paper presents its relevance for teaching where it is used to create an inclusive approach where students and teachers co-create the context and the content for the course within a Masters of Social Practice programme. Co-creative inquiry of this kind resulted in very high engagement of students, remarkably positive feedback about the course, very high standard of assignments and an increased collaboration between students. Peer and self-assessment, especially peer assessment from practitioners in the area of students' practice contributed to integration of theory, practice and experience and proved to be useful not only for students but for peer assessors as well. Students reported about personal integrity that developed during this process and emphasised the importance of the context of inclusiveness which was co-created where all voices were heard and where a range of alternative views were appreciated and explored for the purpose of learning about respecting difference. A summary of findings from this unusual and truly collaborative, student centred, inclusive and inquiry based approach is presented and critically analysed.
\end{abstract}

\section{Key I deas}

- Co-creative inquiry learning engenders competent practitioners who act with integrity.

- Personalisation of prescribed learning outcomes helps in development of a context where students show greater honesty and openness about their goals and beliefs, enables all voices to be heard and all students to be included in the inquiry process regardless of their background and beliefs.

- $\quad$ Self and peer assessment increases quality of student assignments.

Discussion Question 1 How to further develop the method and make it suitable for a range of professional fields?

Discussion Question 2 How to modify this inclusive approach to be suitable for large classes? 


\title{
Pathways into bullying: the place of educational integrity
}

\author{
Deborah Osborne \\ University of Wollongong, Australia
}

\begin{abstract}
It is proposed that educational integrity is the antithesis of bullying, yet in its broadest sense is a pathway into bullying. Broad principles of educational integrity comprise honesty trust, equity, respect, responsibility and inclusion. This paper contributes to the topic by presenting an empirical contribution that develops grounded substantive theory in the field of workplace bullying. The study investigated the process of becoming bullied, being bullied and the consequences for individuals and organisational culture. Grounded theory (GT) analysis of informants' constructions was based on action. A 'pathways' concept emerged. Pathways of dissent and difference characterised by 'standing up' or 'standing out' precipitated and/or escalated the trajectory into bullying. Values constructs and difference from cultural norms underpinned pathways. As bullying became entrenched, bullying cultures featured sham dealing. Transcending governance and fraud occurred in extreme instances. Sham dealing is an 'out of the ordinary' use of organisational structures and practices, characterised by a deceptive abuse of legitimate process. The substantive theory is derived from this sample but the concepts may be transferable. The theory is a crude beginning to encourage further dialogue.
\end{abstract}

\section{Key Findings}

Pathways into bullying

- Dissenters - Dissent varied in strength and was commonly related to issues of educational integrity.

- Outsiders - Standing out from cultural norms included: difference from gender stereotypes; loners; stigma of a bullied identity; holding professional caring values and competence.

Being bullied

- Being bullied emerged as interaction between social structure and agency. Sham dealing occurs at the point where individual agency meets the opposing force of organisational structure protecting itself. Sham dealing emerged as cluster of interacting entities positioning for protection of self and constitutes both bullying and dealing with bullying. Sham dealing is pivotal in social identity.

Effects: Bullying cultures

- A 'bullying culture in the foreground' - characterised by overt direct and indirect use of hierarchical power, punishing innovation, producing acute fractured social relations and high turnover of staff.

- A 'bullying culture in the background' - characterised by covert use of social informal power, group conformity, stifling innovation. Rumours, innuendos and gossip featured. Bullying was normalised, intermittent, turnover of staff lower.

Discussion Question 1 Does this theory offer meaning to those of you who have tacit knowledge? Please can you offer comments as to transferability of findings

Discussion Question 2 Given that our workplaces reflect society how does globalisation impact on reasons why bullying and educational integrity are raising a groundswell of interest today? 


\title{
The various incarnations of an online academic integrity module, or whose responsibility is it anyway?
}

\author{
Alisa Percy, Venkat Yanamandram and Sandra Humphrey \\ University of Wollongong, Australia
}

\begin{abstract}
In the development and delivery of a faculty-based online academic integrity module designed to orient a diverse student cohort to the Faculty's expectations regarding the use of evidence and referencing convention, a number of questions began to emerge out of the continual problematics surrounding its implementation. This paper will provide an overview of the changing design and location of the module since its inception in 2007. The authors reflect on the four incarnations of the module: (i) the compulsory embedded module; (ii) the compulsory disembedded module; (iii) the voluntary disembedded module; and (iv) the voluntary embedded module. In unpacking each of these incarnations, the discussion will address the specific sets of problems that the faculty faced in developing a solution to the 'problem of student plagiarism' in the faculty, and reflect on these problems in relation to the question of whose responsibility it is anyway.
\end{abstract}

\section{Key I deas}

- An educational approach to fostering academic integrity can be conceived in multiple ways.

- Unintentional plagiarism is often conceived in terms of the individual students' cultural naivete and skill deficit, ie. a problem with the student.

- This tends to involve a representation of the student as a rational autonomous learner whose needs can be met by explicit instruction in the requisite skill.

- This assumes that skills can and should be taught, and that students will be able to transfer them to a variety of situations.

- Conceiving of skill in this way often precedes the outsourcing of this teaching to 'skill specialists' or learning advisors.

- Something is lost in the persistence of this conception, particularly when the solution is proposed as an 'inoculation' rather than a 'booster' - as risk management rather than pedagogy.

Discussion Question 1 If not simply a problem of skills deficit and cultural naivete, how else might the problem of academic integrity be conceived?

Discussion Question 2 When might we say that educational approaches are merely risk management strategies? 


\title{
A space odyssey: the implications of moving the writing center into the virtual world
}

\author{
Barbara Ramirez \\ Clemson University, USA
}

\begin{abstract}
For decades, traditional writing centers have offered tutoring services in face-toface environments, but with the growing popularity of distance education, many students now need online access to tutoring. To meet this need, some writing centers are exploring the idea of "virtual" tutoring. As we explore options using virtual environments such as Second Life for this purpose, we are confronted with a range of questions about changes in the dynamics of the tutoring process, many of which concern academic integrity.
\end{abstract}

\section{Key I deas}

- $\quad$ Strategies are needed to maintain the boundary between legitimate, effective tutoring and proofreading, rewriting, and prohibited collaboration.

- Methods are needed to train tutors to be effective in virtual environments.

- $\quad$ Safeguards are needed to ensure student academic integrity and ownership.

Discussion Question 1 For moving to a virtual writing center, what modifications need to be made to tutor training?

Discussion Question 2 What technical safeguards need to be in place to ensure student confidentiality and ownership? 


\title{
Electronic portfolios: \\ balancing learning and assessment
}

\author{
Gail Ring \\ Clemson University, USA
}

\begin{abstract}
In 2006, our university instituted a requirement that all undergraduates create and submit a digital portfolio as evidence of academic and experiential mastery of academic competencies. The rationale for this ePortfolio Program is to build a mechanism through which core competencies (Written and Oral Communication; Reasoning, Critical Thinking, and Problem Solving; Mathematical, Scientific, and Technological Literacy; Social Science and Cross-Cultural Awareness; Arts and Humanities; and Ethical Judgment) can be both demonstrated and evaluated. Although the ePortfolio was originally implemented as an assessment tool, its broader educational function is to make students' college education more meaningful and to assess the integrity of the educational process.
\end{abstract}

\section{Key I deas}

- The introduction of an ePortfolio requirement into the college curriculum brings with it concerns about plagiarism and academic integrity.

- The development of an ePortfolio must add value to the undergraduate experience if the initiative is to be successful.

- Using an ePortfolio as both learning tool and an assessment tool creates a tension that needs to be addressed.

Discussion Question 1 How can we design and implement an ePortfolio system that serves multiple purposes, for example can an ePortfolio be an assessment tool and a learning tool?

Discussion Question 2 In what ways does the idea of ownership and publication contribute to the integrity of the student's work? 


\title{
Dialogue and disputation: explorations in the ethics of argumentation
}

\author{
Susan Robinson
}

\begin{abstract}
This paper considers how to harmonize the demands of good scholarship with professional and ethical courtesy towards our colleagues in written and unwritten academic work. In the nineteenth century, W.K.Clifford and William James introduced the notion of an ethics of belief: a set of quasi-moral rules governing the formation of opinions. Using the Clifford/James debate plus J.S.Mill's discussion of freedom of speech as points of departure, this paper takes some first steps towards formulating an ethics of argumentation: a set of principles governing the ways scholars critically dialogue with the views of others. Candidates for such principles in the philosopher's or logician's repertoire include the principle of charity, playing author's or devil's advocate, and injunctions against attacking 'straw man' arguments. We will consider whether our duties to arguments may sometimes override our duties to arguers by discussing Mill's suggestion that some positions are so important to intellectual inquiry that they require people to earnestly advocate them for new audiences. Contemporary constructivist accounts of learning confirm Mill's opinion that some arguments deserve to be revisited for pedagogical purposes.
\end{abstract}

\section{Key I deas}

- There is such a thing as the ethics of belief: a set of quasi-moral dos or donts governing the way we form beliefs.

- The ethics of belief provides a model for developing an ethics of argumentation.

- The so-called principle of charity is an obvious candidate for a principle underlying the ethics of argumentation.

- The good intentions underlying the principle of charity sometimes lead to patronising interpretations of the arguments of other people.

- The principle of charity must be used sensitively if we are to balance the interests of arguers against the interests of the intellectual positions that people propose to us.

Discussion Question 1 How do we balance our duty to engage in inquiry against our responsibilities in handling the writings and ideas of others?

Discussion Question 2 Do our moral and professional duties extend beyond the people proposing arguments to the arguments themselves?

Discussion Question 3 Does the principle of charity in interpretation help or hinder our efforts to understand other people's positions or points of view? 


\title{
Decline in academe
}

\author{
Kim R. Sawyer, Jackie J ohnson and Mark Holub
}

The University of Western Australia

\begin{abstract}
When universities became corporate universities, the constraints that defined universities changed. The values of the old university, of scholarship, truth and freedom, were replaced by the values of the market. Education became a product, the university a firm, and the university system an industry. This paper considers the decline in academe as universities converge towards for-profit corporate universities. The paper explores why universities have become corporations, how they have become corporations, and how academics survive within those corporations. In the corporate university, the academic becomes accountable to management and to students. Collegiality is sacrificed for managerialism, and freedom for accountability. The academic role is inverted. The academic becomes the academic of the production line, producing standardized teaching and research. The paper suggests that the corporate university risks sacrificing too much scholarship and too much freedom for the principles of the market, thereby diluting the integrity of the university.
\end{abstract}

\section{Key I deas}

- In the corporate university, the values of the market have replaced the values of scholarship.

- Academic integrity has declined as academics trade- off revenue for principles.

Discussion Question 1 Can the corporate university afford to destroy academic freedom?

Discussion Question 2 Can academic integrity survive? 


\title{
Ethical tensions in a disability label?
}

\author{
Sandra Seymour \\ Victims of Crime Disability Training Program, WWILD Inc
}

\begin{abstract}
This paper explores the ethical tensions that happen in community education when we name and label people. The Victims of Crime Disability Training Program is a small state wide non government agency funded by the Department of Communities in Brisbane. Our role is to provide community education on the issues that make people with intellectual disability vulnerable to crime and ways to work with them in the criminal justice system. In our practice we know that there is no homogeneous grouping of "intellectually disabled" yet we are constantly imposing a homogeneous identity when we talk about "them" in training. This paper draws on the work of Judith Butler and Stuart Hall to examine how language brings people into being in ways that they may not recognise themselves. Here we are exploring the constant tension this creates in the work of an organisation that strives to work alongside people and rejects notions of ablism.
\end{abstract}

\section{Key I deas}

- To consider how language can cause us ethical tensions.

- To explore how language inscripts bodies.

Discussion Question 1 What happens to our identity when we are named and labelled in ways that we do not recognise ourselves?

Discussion Question 2 How can we escape the confines of language, names and labels? 


\title{
The effectiveness of plagiarism detection software as a learning tool in academic writing education
}

\author{
Brad Stappenbelt \\ University of Wollongong, Australia \\ Chris Rowles \\ The University of Western Australia
}

\begin{abstract}
Plagiarism detection software is commonly employed in a punitive capacity, detecting plagiarism after assignment submission. As an alternative to this approach, online plagiarism detection software was adopted as a learning tool for students instead. A trial was conducted in the foundation unit of the professional development component of the engineering degree at the University of Western Australia. Prior to the use of plagiarism detection software as a learning tool, efforts to instruct students regarding proper referencing and paraphrasing did not result in commensurate decreases in the levels of plagiarism detected. Many student assignments submitted displayed at the very least careless source acknowledgement. As part of the trial, students were given individual access to the software to self-assess their work as often as required prior to submission. The plagiarism detection algorithm assignment-originality statistics across three substantial written assignments throughout semester revealed continual and substantial improvement in student ability to avoid plagiarising. Through the use of this software, students were facilitated to learn how to properly acknowledge sources and improve their paraphrasing. This was accompanied by a dramatic decrease in the reportable incidence rates of plagiarism. Student perception of the use of plagiarism detection software in this capacity was also very positive.
\end{abstract}

\section{Key I deas}

- Plagiarism detection software was adopted as a learning tool rather than as a plagiarism policy enforcement mechanism.

- The approach encouraged more experiential learning.

- The approach relieved some of the burden for teaching staff checking student work prior to submission.

- The approach assisted in building a community of academic integrity. Adopting plagiarism detection software as a learning tool, the educator's role was seen more as assisting writing skill development rather than policing plagiarism.

- There was a substantial $79 \%$ decrease in assignment first-draft mean level of plagiarism from the first to the second written assignment.

- There were no cases of plagiarism detected in the final assignment across approximately 620 students.

- Most students strongly agreed that access to the online plagiarism detection tool had been useful in their report preparations.

- Most students strongly agreed that the use of the online plagiarism detection tool had improved their ability to avoid plagiarising.

Discussion Question 1 What, if any, is the role of plagiarism detection software in developing and nurturing a community of academic integrity?

Discussion Question 2 Does the use of detection software facilitate the educational objective of transferring to students a sense of ethics and morality regarding plagiarism? 


\title{
Plagiarism, ethics and education: where to now?
}

\author{
Wendy Sutherland-Smith \\ Monash University, Australia \\ Sue Saltmarsh \\ Charles Sturt University, Australia
}

\begin{abstract}
Agreement within tertiary institutions about the most effective ways to deal with plagiarism continue to be fraught with tension. Institutions often opt for multiple means of deterrence, including electronic and human detection; revamped policies and procedures to increase deterrence and instigating an overall increased awareness of academic integrity issues within the academic community. One approach focuses on ethics as a vehicle in overcoming plagiarism. Universities add compulsory 'ethical' units or segments within existent subjects to 'cover' plagiarism and other issues of academic integrity in programs. However, how is this approach operating in practice? Are students sustaining notions of ethical practice throughout their courses of study and into the workplace? This session seeks to tease out some of the current 'ethical approaches' to plagiarism and collaboratively examine what appears to be working or not working and why. In particular, common academic practices will form a focal point for discussion, in terms of the notion of ethical engagement with students.
\end{abstract}

\section{Key I deas}

The term 'ethics' is as widely interpreted and as problematic as the term 'plagiarism' in its application within universities.

'Ethics' is used as a political and ideological band-aid for issues of academic integrity sounds good in theory but may achieve little in practice.

Sharing ideas/ practices about 'ethics' and plagiarism management may promote deeper engagement with notions of ethics more broadly.

Discussion Question 1 How are we integrating 'ethics' in plagiarism management within units, courses and teaching approaches?

Discussion Question 2 What is working/not working and what will it take to improve ethical approaches to plagiarism management? 


\title{
Scholarly practice the Australian way: an academic skills course for postgraduate students
}

\author{
Kirsten Wahlstrom, Helen J ohnston and Chris Steketee \\ University of South Australia
}

\begin{abstract}
International students in postgraduate coursework degrees experience many challenges in adapting to Australian writing conventions. Too often comprehending and meeting referencing requirements for assignments has proved challenging, and has cost students dearly in terms of academic success and lost face. A new pedagogical approach is needed. In this paper we describe a course which fosters inclusivity and communication. The course focuses on academic, professional and information literacies, and its design acknowledges that Australian scholarly practice is unfamiliar to many students. Our pedagogical approach is dialogic, involving students in many and various learning activities. Acknowledgement of students' prior experience, cultural difference and transitional needs is integral to classroom discussion. The course is taught by a team of staff from computer science, career services, the library, and language and learning support, and the curriculum is transparently scaffolded by assessment. We present evidence of the course's success in meeting its goals including the adoption of Western academic conventions, and of high student satisfaction. The course is being adapted to other disciplines.
\end{abstract}

\section{Key I deas}

In our teaching context, where academic integrity has been a problem for international students, students who are unaccustomed to Western scholarly practice learn about referencing and academic integrity through a supportive and positive curriculum.

International students respond positively and successfully to a course that respects cultural and educational difference, introduces new cultural norms and idiom, and develops their capacities for scholarly observation, reflection and critique.

An inclusive curriculum can be based on mutual respect, offer multiple and diverse opportunities to learn, and meet practical, immediate and longer term learning needs.

Discussion Question 1 What are the benefits of a specific postgraduate course, compared to an approach which embeds writing, referencing and cultural skills in existing curriculum?

Discussion Question 2 What are the challenges of extending this approach to other disciplinary contexts? 


\title{
Partnering with the academy to enhance educational integrity: lessons learnt at the coalface
}

\author{
Dallas Wingrove and Kylie Budge \\ RMIT University, Australia
}

\begin{abstract}
Educational integrity lies at the heart of a university's capacity to contribute to the wider social context through learning, teaching, research and scholarship. As our institution and the sector identifies, the capacity of the university to contribute to a functional and meaningful society is predicated upon this core value. In this paper, the authors who are both academic developers present two case studies where the imperative for change was to support and enhance the educational integrity of learning and teaching programs within the disciplines of engineering and construction management in our university. In doing so, we critically reflect on our experience of partnering with academics outside our discipline and explore the questions: What different conceptions of educational integrity can emerge when different disciplinary tribes are compelled to partner? How do academic developers negotiate change in light of these different conceptions, and ensure that the core principles of honesty, trust and respect are played out on the ground? This paper seeks to build knowledge of how academic developers, through partnership with diverse academic communities, can actively foster a capacious and collective ownership of, and responsibility for, educational integrity in higher education.
\end{abstract}

\section{Key I deas}

- Academic development as an agent for change to support educational integrity: institutional enablers and impediments to realising it's potential

- Converging and diverging conceptions of educational integrity amongst the academic community- the individual, the discipline community, the institution- the implications for the enhancement of educational integrity

- Understanding, respecting and building on diverse ways of knowing and academic identity to foster educational integrity

- Defining and negotiating curriculum and pedagogic change to enhance educational integrity

- Educational integrity: top down policy initiatives vs. support for curriculum and pedagogic reform on the ground the institutional implications

- Academic developers as reflective practitioners.

Discussion Question 1 How can universities sustain and enhance educational integrity by building on the different perceptions of educational integrity held by their academic communities?

Discussion Question 2 What are the challenges, logistics and benefits of collaborating across the discipline borders to enhance educational integrity? 


\title{
The customer isn't always right: limitations of "customer service" approaches to education, or why higher education is not Burger King
}

\author{
Daniel E. Wueste \\ Clemson University, USA \\ Teddi Fishman \\ Clemson University, USA
}

\begin{abstract}
The increasingly popular trend of conceptualizing education in terms of "customer service" is, in some ways, attractive. It encourages educators to think in terms of meeting students' needs and to develop innovative ways to deliver their "product." In other ways, however, it fails to convey the essential collaborative, participatory, reciprocal relationship that is central to effective teaching and learning. With respect to academic integrity, the customer service model also obscures students' roles and responsibilities. In this paper, we will identify some of the ways this model-in which the customer expresses a need and the vendor meets that need in exchange for payment-provides an inappropriate metaphor for understanding the project of teaching and learning (i.e., education). When embraced uncritically, the model has the potential both to undermine education and at the same time derail efforts to develop and sustain a culture of integrity. After identifying this model's shortcomings, we will suggest ways to develop and promote a more robust model in which faculty and students work together toward a shared purpose while recognizing and embracing their interlocking responsibilities.
\end{abstract}

\section{Key I deas}

- In the "customer service" model of education, students increasingly expect to be given what they have paid for rather than working actively with faculty to achieve a common goal.

- This model's presupposition that responsibility for students' education rests solely with the faculty who "deliver" it is at odds with effective academic integrity practice which requires that students play an active part in their own education.

- Recognizing and resisting the customer service model is necessary, for reasons relating to both academic integrity and the educational enterprise itself.

Discussion Question 1 To what extent are students' unexamined assumptions about education being a commercial exchange already affecting academic integrity efforts?

Discussion Question 2 Given that students already assume this model, how might we change that perception? 


\title{
The perception of referencing and plagiarism amongst students coming from confucian heritage cultures
}

\author{
Molly Yang \\ Central Queensland University, Australia \\ Stephen Lin \\ ABC Immigration \& Education Consultants, Australia
}

\begin{abstract}
This paper attempts to explore the perception of referencing and plagiarism amongst students coming from Confucian cultural heritage. The focus of this paper concentrates on these students' learning approaches and styles and associated problems. This paper evaluates research conducted among all such students who are studying in Australia. The paper identifies both positive and negative perceptions and highlights several misperceptions on students from Confucian cultural heritage that are commonly held by Western academics. Finally, the paper presents an overview of strategies that might be adopted by Western academics in order to make these students' experiences in Australian universities more enjoyable and successful.
\end{abstract}

\section{Key I deas}

- This paper examines the differences in perception of plagiarism amongst Chinese students who have been relying on rote learning and blending ideas and concepts with their own original thoughts.

- As in a typical examination, the memory of knowledge would be tested through short answers, Multiple Choices and Short Essays. Their practice research and hand-on skills are less emphasized.

- Borrowed ideas are widely accepted to advance their argument, esp. ideological ones;

- Referencing has less importance in their scholarship and academic accomplishment;

- To contribute to the mutual pool of human knowledge is perceived as a duty and privilege, to be widely copied or quoted are good indication of their success.

- Intellectual properties are bestowed by some sacred blessing, traditionally, so to reap financial awards are not part of Confucianism.

- Students are picking up Australian requirement for proper reference and acknowledgement of others' works.

- $\quad$ Some have embraced the ideas, some with reluctance.

Discussion Question 1 Does strict requirement of reference contribute to the students' learning?

Discussion Question 2 Shall we encourage a free contribution of ideas to advance the intellectual and economical well being of the human race? 


\title{
Can we reliably determine intent in cases of plagiarism?
}

\author{
J on Yorke, Kathryn Lawson and Graham McMahon \\ Curtin University of Technology, Western Australia
}

\begin{abstract}
A review of the literature relating to plagiarism suggests that there is substantial variability in approach between institutions. Some institutions tend to view all occurrences of plagiarism as academic misconduct, whilst others take a more graded view - articulated through policy and procedures that aim to quantify 'levels' of severity. Measured approaches such as these tend to rely on guides to help assess the level of severity, typically encompassing the experience of the student, the amount of material plagiarised, and the likelihood of an intention to deceive. Such judgements lead to a graded response to the student which can result in a wide range of outcomes, from educational guidance and support to expulsion from the institution. However, the intent to deceive can be extremely difficult to establish. This paper will draw on a desktop study of institutional policies and procedures in Australia and other countries to sample and summarise the myriad approaches to the definition and determination of (specifically) intent in plagiarism. Based on the findings of this review, a number of potential and currently used measures are presented for discussion.
\end{abstract}

\section{Key I deas}

- Intent to plagiarise is often cited in institutional policy

- Intent is often used to determine outcomes in cases of plagiarism

- Evidence suggests that intent is very difficult to measure

- A review of institutional policy and procedures shows variation in approach

Discussion Question 1 How effective are these existing and putative measures of 'intent'?

Discussion Question 2 Can we reliably determine intent in cases of plagiarism? 


\section{List of Delegates}

\begin{tabular}{|c|c|}
\hline Tracey Bretag & University of South Australia \\
\hline Kylie Budge & RMIT University \\
\hline Peter Curtin & na \\
\hline Ken Cruickshank & University of Wollongong \\
\hline Kim Draisma & University of Wollongong \\
\hline Julianne East & La Trobe University \\
\hline Teddi Fishman & Clemson University \\
\hline Katie Freund & University of Wollongong \\
\hline David Griffiths & University of Wollongong \\
\hline Margaret Green & University of South Australia \\
\hline Gabrielle Grigg & The University of Melbourne \\
\hline Todd Hartle & University of Southern Queensland \\
\hline Clair Hughes & The University of Queensland \\
\hline Bronwyn James & University of Wollongong \\
\hline Michael J ones & University of Wollongong \\
\hline Lindy Kimmins & University of Southern Queensland \\
\hline James Lee & Queen's University \\
\hline Fande Liu & The University of Adelaide \\
\hline Petria McGoldrick & University of Wollongong \\
\hline Ursula McGowan & The University of Adelaide \\
\hline Graham McMahon & Curtin University of Technology \\
\hline Susan Madsen & Utah Valley University \\
\hline Brian Martin & University of Wollongong \\
\hline Jennifer Martin & Griffith University \\
\hline Judith Marychurch & University of Wollongong \\
\hline Chris Moore & University of Wollongong \\
\hline Paul Moore & University of Wollongong \\
\hline Calvin Murty & National University of Singapore \\
\hline Ksenija Napan & Unitec, New Zealand \\
\hline Deborah Osborne & University of Wollongong \\
\hline Meeta Padmanabhan & University of Wollongong \\
\hline Lee Partridge & The University of Western Australia \\
\hline Alisa Percy & University of Wollongong \\
\hline Susan Robinson & University of South Australia \\
\hline Ann Rogerson & University of Wollongong \\
\hline Celeste Rossetto & University of Wollongong \\
\hline Sue Saltmarsh & Charles Sturt University \\
\hline Sandra Seymour & Victims of Crime Disability Training \\
\hline Adrian Stagg & University of Southern Queensland \\
\hline Brad Stappenbelt & University of Wollongong \\
\hline Chris Steketee & University of South Australia \\
\hline Wendy Sutherland-Smith & Monash University \\
\hline Tom Tanhchareun & University of New South Wales \\
\hline Ruth Walker & University of Wollongong \\
\hline
\end{tabular}

tracey.bretag@unisa.edu.au

kylie.budge@rmit.edu.au

pcurtin@bigpond.net.au

ken_cruickshank@uow.edu.au

kimd@uow.edu.au

j.east@latrobe.edu.au

TFISHMA@clemson.edu

kfreund@uow.edu.au

griffd@uow.edu.au

margaret.green@unisa.edu.au

g.grigg@pgrad.unimelb.edu.au

todd.hartle@usq.edu.au

clair.hughes@uq.edu.au

bjames@uow.edu.au

mjones@uow.edu.au

lindy.kimmins@usq.edu.au

」im.Lee@queensu.ca

fande.liu@adelaide.edu.au

petria_mcgoldrick@uow.edu.au

ursula.mcgowan@adelaide.edu.au

g.mcmahon@curtin.edu.au

madsensu@uvu.edu

bmartin@uow.edu.au

j.martin@griffith.edu.au

judithm@uow.edu.au

moorenet@gmail.com

paulmoor@uow.edu.au

regcm@nus.edu.sq

knapan@unitec.ac.nz

dno850@uow.edu.au

meeta@uow.edu.au

lee.partridge@uwa.edu.au

alisa@uow.edu.au

susan.robinson@unisa.edu.au

annr@uow.edu.au

celeste@uow.edu.au

ssaltmarsh@csu.edu.au

Program sandi.voc@wwild.org

stagg@usq.edu.au

brads@uow.edu.au

Chris.Steketee@cs.unisa.edu.au

wendy.sutherland-smith@education.monash.edu.au

tom.tanhchareun@gmail.com

rwalker@uow.edu.au 
Margaret Wallace

Dallas Wingrove

Daniel Wueste

Venkat Yanamandram

Jennifer Yee
University of Wollongong

RMIT University

Clemson University

University of Wollongong

National University of Singapore mwallace@uow.edu.au

dallas.wingrove@rmit.edu.au

ERNEST@clemson.edu

venkaty@uow.edu.au

regymsj@nus.edu.sg

Delegate list as at September 21, 2009. Updated list to be published on website.

Please save the date for

\section{5th Asia Pacific Conference on Educational I ntegrity (5APCEI)}

The University of Western Australia

Perth, Western Australia

\section{6-28 September 2011}

Conference website:

http:// www.catl.uwa.edu.au/5APCEI
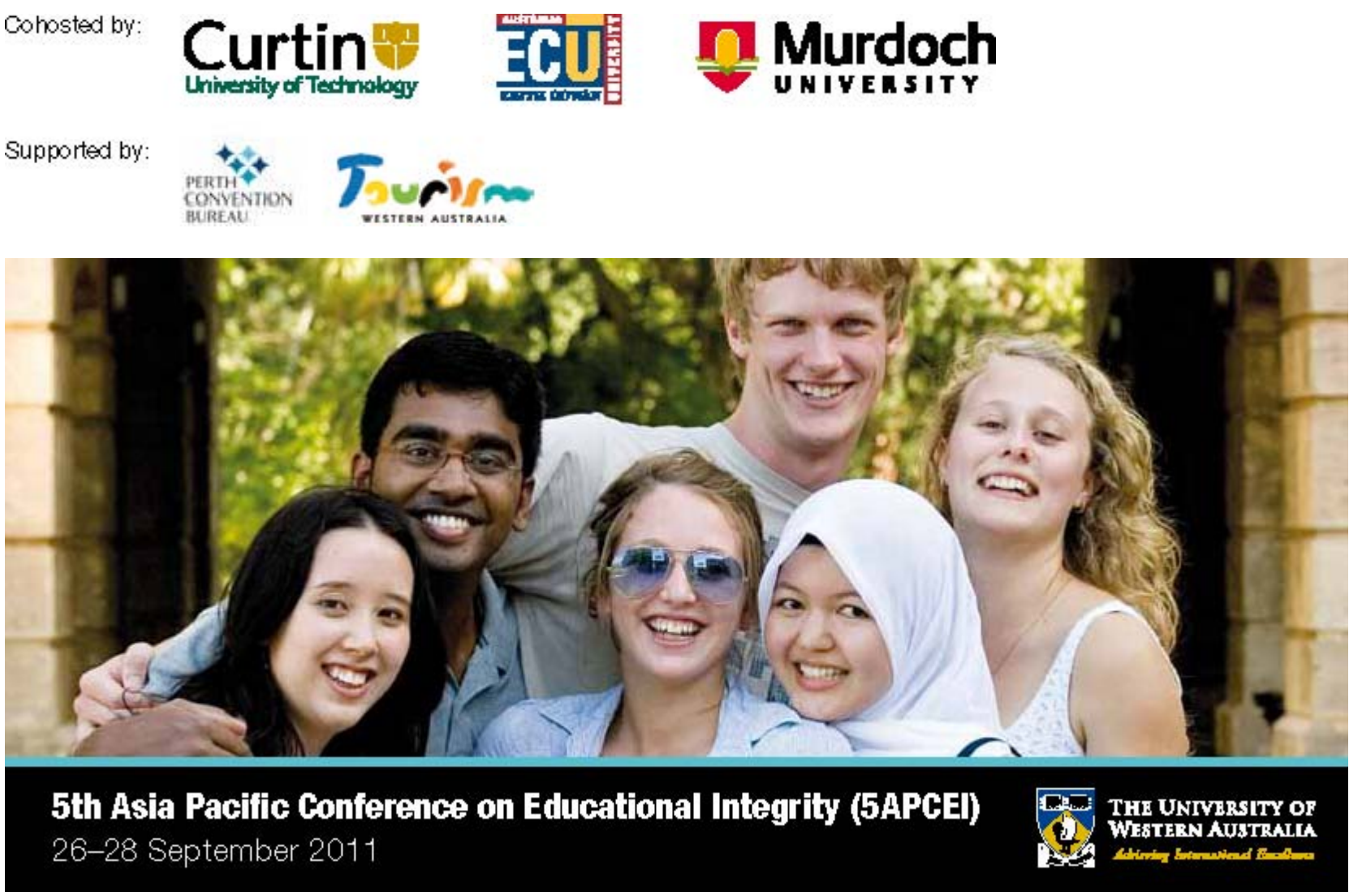